\title{
Evaluation of The Aggression Suppression Program, Milwaukee, Wisconsin
}


This publication is distributed by the U.S. Department of Transportation, National Highway Traffic Safety Administration, in the interest of information exchange. The opinions, findings, and conclusions expressed in this publication are those of the authors and not necessarily those of the Department of Transportation or the National Highway Traffic Safety Administration. The United States Government assumes no liability for its contents or use thereof. If trade or manufacturers' names or products are mentioned, it is because they are considered essential to the object of the publication and should not be construed as an endorsement. The United States Government does not endorse products or manufacturers. 


\begin{tabular}{|c|c|c|}
\hline DOT HS 809395 & 2. Govermment Accession No. & 3. Recipient's Catalog No \\
\hline \multirow{2}{*}{\multicolumn{2}{|c|}{$\begin{array}{l}\text { 4. Title and Subtitle } \\
\text { Evaluation of the Aggression Suppression Program, Milwaukee, Wisconsin }\end{array}$}} & $\begin{array}{l}\text { 5. Repon Date } \\
\text { May } 2001\end{array}$ \\
\hline & & 6. Performing Organization Code \\
\hline \multicolumn{2}{|c|}{$\begin{array}{l}\text { 7. Author(s) } \\
\text { A.T. McCartt, W.A. Leaf, T.L. Witkowski, M.G. Solomon }\end{array}$} & 8. Performing Organization Report No. \\
\hline \multirow{2}{*}{\multicolumn{2}{|c|}{$\begin{array}{l}\text { 9. Perforning Organization Name and Address } \\
\text { Preusser Research Group, Inc. } \\
7100 \text { Main Street } \\
\text { Trumbull, CT } 06611\end{array}$}} & 10. Work Unit No. (TRAIS) \\
\hline & & $\begin{array}{l}\text { 11. Contract or Grant No. } \\
\text { DTNH22-98-H-05107 }\end{array}$ \\
\hline \multirow{2}{*}{\multicolumn{2}{|c|}{$\begin{array}{l}\text { 12. Sponsoring Agency Nane and Address } \\
\text { U.S. Department of Transportation } \\
\text { National Highway Traffic Safety Administration } \\
400 \text { Seventh Street, S.W. } \\
\text { Washington, D.C. } 20590\end{array}$}} & 13. Type of Report and Period Covered \\
\hline & & 14. Sponsoring Agency Code \\
\hline
\end{tabular}

15. Supplementary Notes

Joe Ann O'Hara served as NHTSA Contracting Officer's Technical Representative for the study, and Terry L. Witkowski served as the Project Manager.

16. Abstract

In October 1998, the Milwaukee Police Department was awarded the first federally-funded Aggressive Driving Demonstration Grant by the U.S. Department of Transportation. This 18-month demonstration project was designed to study aggressive driving and provide information and enforcement results to law enforcement agencies across the U.S. The total grant of $\$ 650,241$ included a local match of $\$ 173,716$. Milwaukee competed with law enforcement agencies from 26 other metropolitan areas for this grant. The goals of the project were to develop and evaluate an innovative enforcement strategy to reduce aggressive driving and to develop and evaluate public information and education programs to discourage aggressive driving. The first six months were devoted to gathering baseline data and developing the publicity plan and enforcement schedule. Milwaukee launched the sixmonth enforcement and awareness phase on March 30,1999. This phase was organized into a series of three-week enforcement and publicity "sub-theme" campaigns, each focusing on a specific traffic offense commonly associated with aggressive driving and each with a distinctive slogan. The final six months provided time for the project to be evaluated and this report to be prepared. The process evaluation indicated the program was exemplary in terms of planning, coordination, and implementation. Considerable special enforcement was undertaken, and a number of innovative strategies, including innovative technologies, were useful in identifying and apprehending aggressive drivers. Based on an outcome evaluation, the program demonstrated the effects of targeted enforcement. More citations were issued for violations associated with aggressive driving (not just speed citations); red light-running behaviors changed at targeted intersections; and crash reduction was demonstrated citywide, with greater reductions on corridors with targeted enforcement. Programs of this type could likely be improved with paid media as well as earned media so that more visible, focused media attention could be gained.

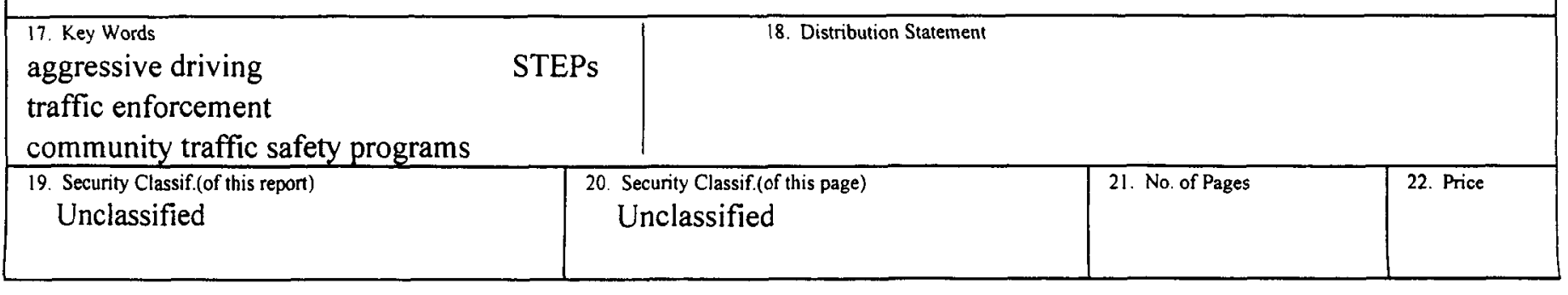




\section{DEPARTMENT OF TRANSPORTATION \\ NATIONAL HIGHWAY TRAFFIC SAFETY ADMINISTRATION}

TECHNICAL SUMMARY

\begin{tabular}{l|l}
\hline \hline CONTRACTOR & CONTRACT NUMBER \\
Preusser Research Group, Inc. & DTNH22-98-H-05107 \\
\hline REPORT TITLE & REPORT DATE \\
Evaluation of the Aggression Suppression Program, Milwaukee, Wisconsin & May 2001 \\
\hline
\end{tabular}
REPORT AUTHOR(S)

A.T. McCartt, W.A. Leaf, T.L. Witkowski, M.G. Solomon

\section{Background}

In October 1998, the Milwaukee, Wisconsin, Police Department was awarded the first federally-funded Aggressive Driving Demonstration Grant by the U.S. Department of Transportation, National Highway Traffic Safety Administration (NHTSA). This 18-month demonstration project was to study aggressive driving and provide information and enforcement results to law enforcement agencies across the U.S. The total grant of $\$ 650,241$ included a local match of $\$ 173,716$. Milwaukee competed with law enforcement agencies from 26 other metropolitan areas for this grant. The goals of the project were to develop and evaluate an innovative enforcement strategy to reduce aggressive driving and to develop and evaluate the effectiveness of public information and education programs to discourage aggressive driving.

The project was divided into three six-month phases. The first phase was devoted to gathering baseline data and developing the publicity plan and enforcement schedule. The second phase was devoted to conducting the enforcement effort and increasing public awareness about aggressive driving and the traffic violations that are generally associated with aggressive driving. The final phase provided time for the project to be evaluated and this report to be prepared.

On March 30, 1999, Milwaukee launched the Aggression Suppression Program, the enforcement and public information and education phase of this project. Coordinated by the City of Milwaukee Safety Commission, Aggression Suppression was a six-month program that combined 1) intensified general and targeted innovative enforcement, incorporating innovative enforcement strategies and technologies, with 2) publicity about the heightened enforcement and the dangers of aggressive driving.

NHTSA's primary objectives for the project were as follows:

- Determine whether highly publicized intensified enforcement of aggressive driving offenses results in positive changes in drivers' attitudes and behaviors.

- Test the willingness, and the ability, of law enforcement officers to enforce a wide range of aggressive driving behaviors in addition to speeding.

- Test the feasibility and effectiveness of alternative public awareness and enforcement strategies, including the use of innovative technologies to detect aggressive driving actions.

- Further the state of knowledge about defining and measuring aggressive driving. 


\section{Program Description}

The program was planned and coordinated by the City of Milwaukee Safety Commission, which also functions as the Safety Division of the Milwaukee Police Department; the Safety Commission also was responsible for developing and implementing the public awareness efforts. An advisory committee included representatives from the City of Milwaukee Police Department; the Milwaukee County Office of the Sheriff; three suburban enforcement agencies; the Wisconsin Department of Transportation; the City's Infrastructure Service Division, Department of Public Works; and Preusser Research Group, Inc., which evaluated the program.

The program had the following elements:

- A public awareness campaign focusing on specific aggressive driving actions and coordinated with the enforcement program.

- Heightened and innovative enforcement directed at unsafe driving throughout the area, and also targeting specific aggressive driving offenses, specific locations, and times of heavy traffic congestion.

- Testing innovative enforcement technologies to detect, apprehend, and convict violators.

- Training officers in the enforcement of aggressive driving offenses.

- A comprehensive evaluation of program effort and results.

Following the enforcement program kick-off, the remainder of the six-month enforcement program was organized into a series of three-week enforcement and publicity "subtheme" campaigns. Each campaign focused on a specific traffic offense generally associated with aggressive driving, had a distinctive descriptive slogan, and was launched by a press conference hosted by one of the participating enforcement agencies. The publicity and enforcement efforts were designed to change the attitudes and behaviors of all drivers in Milwaukee. Enforcement was targeted to specific high-crash roadway corridors and intersections within Milwaukee County and to times of heavy traffic congestion.

\section{Results}

The process evaluation indicated that the Aggression Suppression Program was exemplary in terms of planning, coordination, and implementation. The activities were well documented, and all evidence indicated that the program was fully implemented as planned, with strong "buy-in" from all partners.

All 20 enforcement agencies in the City and County participated in both the publicity and the enforcement efforts. To support enforcement of aggressive driving offenses, the project funded 5,700 patrol hours and 900 administrative and supervisory hours in the City of Milwaukee Police Department and 2,215 patrol hours in the Office of the Milwaukee County Sheriff. The law enforcement agencies of three suburban cities engaged in 1,200 hours of special aggressive driving enforcement, supported by State Highway Safety "Section 402" funding. Fifteen additional suburban law enforcement agencies voluntarily participated in the effort without special funding. A number of innovative enforcement strategies and technologies were tested. These included, for example, in-vehicle video cameras, plainclothes "spotters" placed at intersections, laser speed detection devices, laser devices equipped with technology to measure the distance between cars, electronic display boards to display traveling speeds, a specially developed roll call videotape, magnetic “Aggressive Driving Patrol" vehicle signs, and unconventional patrol vehicles. 
Considerable earned media coverage was generated, especially at the outset, and numerous educational materials were developed and distributed. The series of sub-theme enforcement and publicity campaigns, and the rotation of the press conferences among the participating law enforcement agencies, helped to sustain media interest and to secure the "buyin" of participating law enforcement agencies. Without paid advertising, however, it is doubtful that the campaign would have been able to saturate the media market.

The program succeeded in targeting enforcement to certain locations and certain times. The program was clearly successful in broadening enforcement efforts to target a wide range of aggressive driving offenses in addition to speeding violations. Based on a comparison of the 1999 program period to the comparable six months in 1998, there were large percentage increases in the numbers of citations issued by the City of Milwaukee Police Department and the Office of the Milwaukee County Sheriff for non-speed aggressive traffic violations. Note that these data do not include citations for alcohol-impaired driving, seat belt violations, or operating after revoked/suspended license).

\begin{tabular}{|c|c|c|c|}
\hline \multicolumn{4}{|c|}{$\begin{array}{c}\text { Citations for Aggressive Driving Offenses } \\
\text { City of Milwaukee Police Department and } \\
\text { Office of the Milwaukee County Sheriff } \\
\text { April - September 1998, 1999 }\end{array}$} \\
\hline & 1998 & 1999 & $\begin{array}{c}\% \text { Change } \\
1998 / 99\end{array}$ \\
\hline Office of the Milwaukee County Sheriff & & & \\
\hline Non-Speed Aggressive Traffic Citations & 2,205 & 3,424 & +55.2 \\
\hline Speed Citations & 12,647 & 11,866 & -6.2 \\
\hline City of Milwaukee Police Department & & & \\
\hline Non-Speed Aggressive Traffic Citations & 9,528 & 12,378 & +29.9 \\
\hline Speed Citations & 13,994 & 14,376 & +2.7 \\
\hline
\end{tabular}

For the most part, the innovative equipment aided in enforcing aggressive driving offenses. The speed display boards, in-vehicle video cameras, and laser speed detection devices were well received by officers. Officers were less enthusiastic about distance-between-cars laser technology; the process to obtain accurate measurements of distances proved complex. Enforcernent agencies identified strategies that were particularly effective, for example, the roll call videotape, distribution of flyers to persons receiving citations, intersection patrols, and rotating the specific offenses targeted.

With regard to changes in motorists' driving behaviors, videotaping traffic at 10 intersections targeted for special enforcement, and 10 comparison intersections, was a feasible method for measuring the extent of red light-running. The percent egregious red light-running (of light cycles observed) declined at the targeted intersections from $6.5 \%$ during the pre-program period to $4.9 \%$ during the mid-program period, but increased at the comparison intersections from $2.9 \%$ to $12.7 \%$. The average percentage change at the targeted intersections was significantly different than the average percentage change at the comparison intersections. Although suggestive of program effect, this evidence must be viewed cautiously; enforcement was intensively targeted to these intersections, but heightened enforcement also occurred citywide. 
The program was associated with declines in crashes. As shown in the table below, the overall level of crashes declined significantly in the City, and the reductions were greater on the roadway corridors targeted by special enforcement than on comparison corridors. Similar patterns were identified for multiple-vehicle crashes and for crashes occurring at intersections; in each case, overall crashes declined significantly citywide, and the reductions were greatest on the targeted corridors.

\begin{tabular}{|l|c|c|c|}
\hline \multicolumn{4}{|c|}{ Police-reported Crashes } \\
Target and Comparison Roadway Corridors and Citywide \\
City of Milwaukee, April-September 1998 and 1999
\end{tabular}

Self-reported measures of attitudes and behaviors remained relatively flat across three self-administered surveys of drivers. However, drivers in the mid-program survey were significantly more likely than drivers in the pre-program survey to believe that they would be ticketed for running a red light or running a stop sign. Drivers in the mid-program survey also were more likely to believe that running a red light or driving through a stop sign was always/nearly always a problem. The level of awareness of the specific campaign themes was relatively low in all three waves of the survey. However, statistically significant increases in the level of awareness occurred for the themes of Rude Attitude Patrol, Courtesy Patrol, Space Patrol, and the State's concurrent "Let It Ride" campaign. A much more intensive and/or much more focused publicity effort may be needed to produce greater changes in attitudes and behaviors, especially in a community such as Milwaukee with a long history of highway safety programs and strong enforcement.

In sum, the Aggression Suppression Program demonstrated the effects of targeted enforcement. More citations were issued for aggressive driving types of violations (that is, not just speed tickets were issued); motorist behavior changed at targeted intersections; and crash reduction was demonstrated citywide, with greater reductions on corridors with targeted enforcement. Future programs of this type would be enhanced if they could generate more visible and more focused media attention.

"PREPARED FOR THE DEPARTMENT OF TRANSPORTATION, NATIONAL HIGHWAY TRAFFIC SAFETY ADMINISTRATION UNDER CONTRACT NO.DINH22-98-H-05107. THE OPINIONS, FINDINGS, AND CONCLUSIONS EXPRESSED IN THIS PUBLICATION ARE THOSE OF THE AUTHORS AND NOT NECESSARILY THOSE OF THE NATIONAL HIGHWAY TRAFFIC SAFETY ADMINISTRATION." 


\section{ACKNOWLEDGMENTS}

This report describes the results of an evaluation of the Aggression Suppression Program undertaken in Milwaukee, Wisconsin. The authors would like to acknowledge the agencies that provided the information needed to conduct the evaluation.

As the coordinating agency for the program, the Safety Commission, City of Milwaukee Police Department, provided numerous documents related to the planning and progress of the program, as well as copies of the program's publicity materials. The Traffic Division, Milwaukee Police Department, and the Police Services Bureau, Office of the Sheriff, Milwaukee County, provided detailed historical and current information on traffic citations issued. Both agencies also provided information on the level of their enforcement activities funded by the project and their use of innovative enforcement equipment. Information on traffic citations issued also was provided by the law enforcement departments of the cities of Glendale, Wauwatosa, and West Allis; these agencies received State Highway Safety " 402 " funding to support the special enforcement effort.

The City of Milwaukee's Department of Public Works, Infrastructure Services Division, Transportation Section, Planning and Development provided detailed historical and current crash data. This agency also produced videotapes of traffic at several intersections.

The Traffic Operations Center, Wisconsin Department of Transportation, provided videotapes of traffic on a major highway. 


\section{TABLE OF CONTENTS}

TECHNICAL REPORT DOCUMENTATION PAGE i

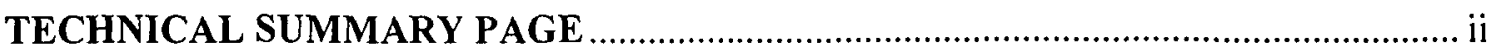

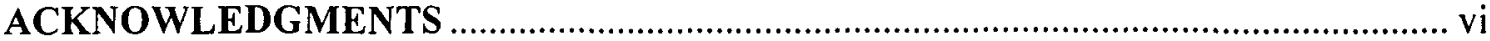

LIST OF TABLES

CHAPTER 1: INTRODUCTION

CHAPTER 2: DESCRIPTION OF AGGRESSION SUPPRESSION PROGRAM ..........4

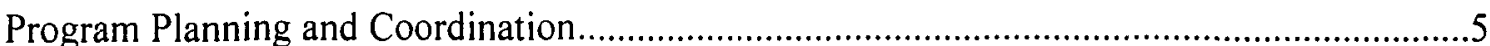

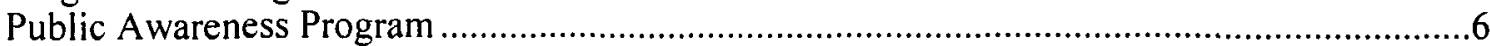

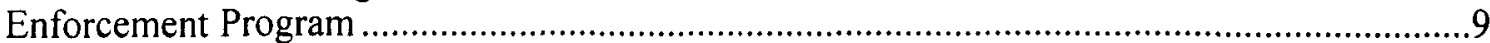

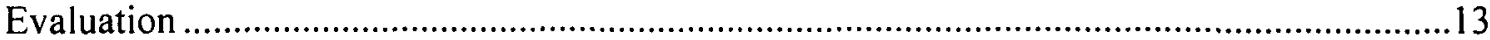

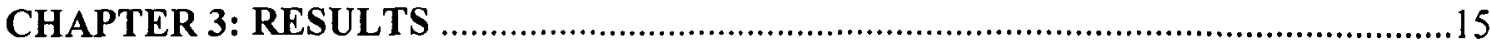

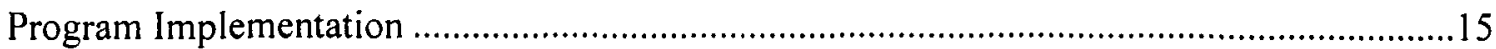

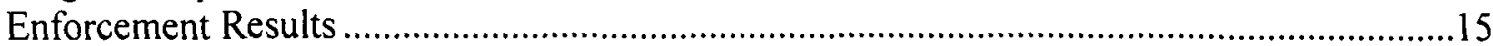

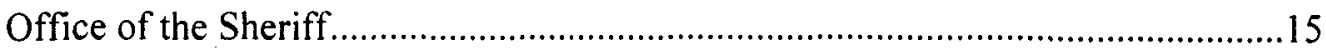

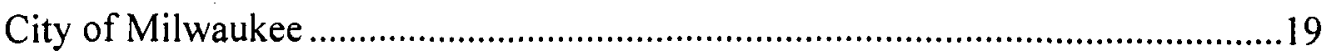

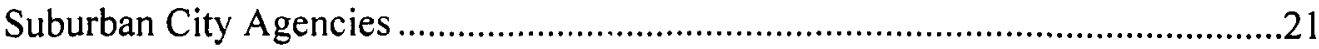

Agencies' Assessment of Enforcement Efforts ..................................................21

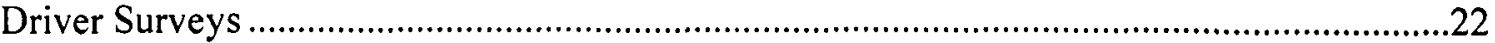

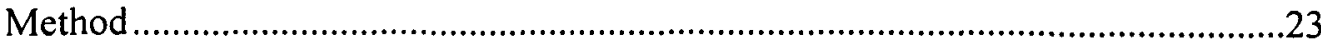

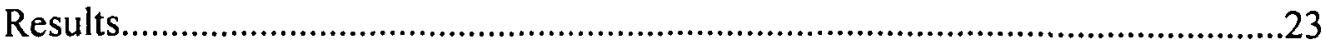

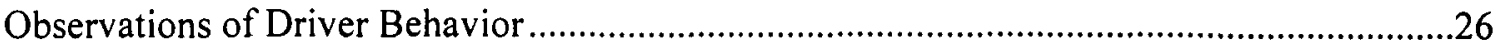

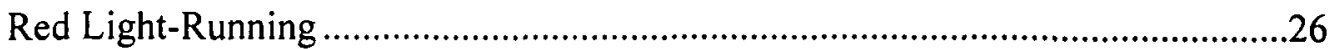

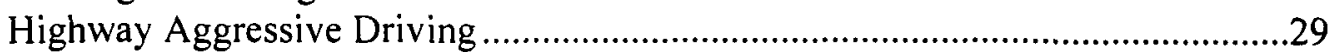

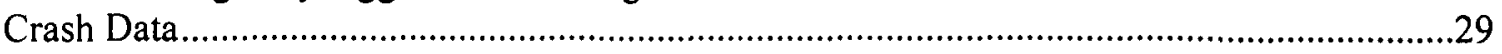

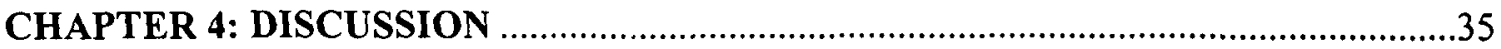

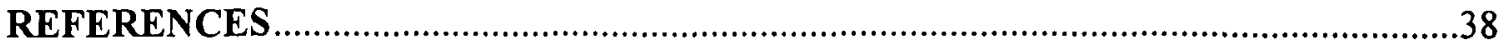




\section{LIST OF TABLES}

Table 2.1: Aggression Suppression Publicity Plan to Support Enforcement Phase, April-

September 1999

Table 2.2: Aggression Suppression Program: Targeted Enforcement Locations in the City of Milwaukee

Table 3.1: Citations for Aggressive Driving Offenses: All Divisions of the Milwaukee County Office of the Sheriff, April -September 1998, 1999.

Table 3.2: Citations for Moving Violations: Traffic Division, Milwaukee County Office of the Sheriff, April -September 1998, 1999

Table 3.3: Citations for Aggressive Driving Offenses: Traffic Division, Milwaukee County Office of the Sheriff Grant Squads, County Match Squads, Regular Patrols, April-September 1999

Table 3.4: Citations for Moving Violations: City of Milwaukee Police Department, April-September 1998, 1999.

Table 3.5: Citations Issued for Aggressive Driving Offenses: City of Milwaukee Police Department Grant Patrols and Non-grant Patrols, April-September 1999 .20

Table 3.6: Perceptions of the Problem Caused by Aggressive Driving Behaviors: Survey of Milwaukee Drivers, March 1999

Table 3.7: Milwaukee Aggression Suppression Program: Observed Red LightRunning Behavior, Target and Comparison Intersections Pre-program, Mid-program, Post-program

Table 3.8: Police-reported Crashes: Target and Comparison Roadway Corridors and Citywide, City of Milwaukee, April-September 1998, 1999

Table 3.9: Multiple-Vehicle Crashes: Target and Comparison Roadway Corridors and Citywide, City of Milwaukee, April-September 1998, 1999

Table 3.10: Crashes at Intersections: Target and Comparison Roadway Corridors and Citywide, City of Milwaukee, April-September 1998, 1999

Table 3.11: Crash-involved Drivers with at Least One Aggressive Factor as Possible Crash Contributing Circumstance: Target and Comparison Roadway Corridors and Citywide, City of Milwaukee, April-September 1998, 1999 


\section{CHAPTER 1: INTRODUCTION}

Over the past few years, the concept of "aggressive driving" has become a major public concern and a growing focus of highway safety programs. According to the National Highway Traffic Safety Administration (NHTSA), aggressive driving occurs when "an individual commits a combination of moving traffic offenses so as to endanger other persons or property." Accordingly, aggressive driving often includes a series of such offenses as following too closely, changing lanes without caution or signal, running a red light, or improper passing. A distinction is made between the traffic offense of aggressive driving and the criminal offense of road rage, defined as "an assault with a motor vehicle or other dangerous weapon by the operator or passenger(s) of one motor vehicle or precipitated by an incident that occurred on a roadway" (NHTSA, 2000, 2001).

Surveys of drivers in various jurisdictions have indicated that drivers believe aggressive driving is a major threat to their safety and a growing problem (RSM, Inc., 1997; McCartt et al., 1998; Preusser Research Group, 1998). In 1997, NHTSA conducted the first national survey on aggressive driving (Boyle, Dienstfrey, and Sothoron, 1998). Key findings of the survey included the following:

- More than six in ten drivers said that another driver's behavior had been a threat to them or their passengers within the past year.

- One-third believed that driving was more dangerous than it was a year ago; factors cited included heavier traffic and more cars (33\%), careless and inattentive drivers (20\%), faster drivers (18\%), and increased speed limits (16\%).

- In addition to unsafe speeds, other types of unsafe driving commonly encountered were weaving in and out of traffic (24\%), tailgating (17\%), driver inattention $(15 \%)$, unsafe lane changes (10\%), unsafe passing (9\%), ignoring stop signs $(8 \%)$, failing to yield $(6 \%)$, drinking and driving $(5 \%)$, and running red lights $(5 \%)$.

- Respondents admitted that they frequently engaged in unsafe behaviors; for example, more than one in four drivers reported entering an intersection just as the light was turning red within the past week.

- A majority believed that there is too little enforcement of tailgating (61\%) and weaving (58\%); a substantial minority, ranging from 40 percent to 44 percent, also believed that more enforcement of other traffic laws, including speeding, is needed.

Various hypotheses about the causes of aggressive driving have been advanced. Experts at a symposium on aggressive driving, convened by NHTSA and the Federal Highway Administration (FHWA), pointed to traffic congestion as a major factor (NHTSA and FHWA, 1999). From 1985 to 1995 in the U.S., the number of registered motor vehicles increased 19 percent, the number of licensed drivers increased 12 percent, and total vehicle miles traveled increased 40 percent. Yet, roadway surface miles increased only 1.1 percent and the number of traffic enforcement officers declined (NHTSA, 2000). Psychologicallybased hypotheses for aggressive driving include feeling endangered, watching other drivers 
break the rules, feeling the need to retaliate, and a culture of disrespect on the roadways (Goehring, 2000). Time pressures may also contribute to aggressive driving; in a survey of New York drivers, 41 percent of drivers reported that they drive more aggressively when they are late or in a hurry (McCartt et al., 1998).

Some states have responded to concerns about aggressive driving by enacting legislation; other states have determined that existing laws are sufficient to address serious violators of traffic laws. In 1998, Arizona became the first state to pass a law creating a specific aggressive driving offense. Other states, including Nevada, Delaware, Rhode Island, and Utah, also enacted legislation to provide for an aggressive driving offense. In 2000, 19 states introduced a total of 36 bills that addressed various aspects of aggressive driving (Savage, 2000).

Although some experts recommend various educational strategies for reducing unsafe driving behavior, enforcement of traffic laws remains the primary countermeasure used by communities to reduce speeding and other forms of unsafe driving. Based on three decades of developing and testing various programmatic strategies, programs of intensive enforcement, when combined with intensive public awareness efforts, have been shown to be effective in reducing unsafe driving behaviors. Official support and the involvement of community organizations further enhance success.

NHTSA's aggressive driving work plan includes the development of enforcement countermeasures and public information and education strategies to inform the public, law enforcement agencies, engineers, and the judiciary about the dangers of aggressive driving and possible solutions (NHTSA and FHWA, 1999). To support the development of "best practices" for implementation by communities (NHTSA 1998, 2000), NHTSA has sponsored aggressive driving enforcement demonstration projects in high traffic density urban areas. The primary objective is to determine whether highly publicized intensified enforcement of aggressive driving offenses, in states with aggressive driving laws, or of offenses generally associated with aggressive driving, in states without specific laws, results in positive changes in drivers' attitudes and behaviors. A second objective is to test the willingness, and the ability, of law enforcement officers to enforce a wide range of "aggressive driving type" violations in addition to speeding. A third objective is to test the feasibility and effectiveness of alternative public awareness and enforcement strategies, including the use of innovative technologies to detect aggressive driving actions. A fourth objective is to develop ways to obtain public and private sector support for a program to reduce aggressive driving. Finally, it is hoped that evaluations of the demonstration projects will further our understanding of how to define and measure aggressive driving.

On March 30, 1999, the City of Milwaukee launched "Aggressive Suppression" a six-month aggressive driving enforcement campaign. The program represented the first aggressive driving enforcement demonstration project funded by NHTSA. Through a strong community coalition, Milwaukee implemented a program that combined intensified general and targeted enforcement by the major enforcement agencies with efforts to educate the public about the dangers of aggressive driving and publicity about the heightened enforcement. 
At least four considerations were key in NHTSA's determination that Milwaukee would be a suitable demonstration site. First, through the City's Traffic Safety Commission, Milwaukee had demonstrated a commitment to traffic safety by previously implementing comprehensive highway safety programs and numerous special traffic enforcement programs. In doing so, Milwaukee had gained experience in conducting a well-coordinated enforcement program involving the key enforcement agencies. Second, extensive historical crash and citation data were available to support the development of a targeted enforcement program. Third, Milwaukee's effort would complement a statewide aggressive driving program, "Let It Ride," implemented by the Wisconsin Department of Transportation. Finally, an evaluation component insured that lessons would be learned for other communities about what "worked and didn't.work." In summary, the Aggression Suppression Program provided an opportunity to further understanding of how to define and measure aggressive driving and how to develop, implement, and evaluate community programs to reduce aggressive driving behaviors.

This report describes Milwaukee's Aggression Suppression Program and presents the results of a process and outcome evaluation of the program. 


\section{CHAPTER 2: DESCRIPTION OF AGGRESSION SUPPRESSION PROGRAM}

The Aggression Suppression Program was designed to combine enforcement and public awareness efforts to effect positive changes in drivers' attitudes and behaviors related to aggressive driving. The following objectives were established:

- Successfully implement the project as designed, especially with regard to successful involvement of the media.

- Increase the number of citations for violations considered aggressive driving offenses, including citations issued by grant-funded officers and by all other officers detailed to traffic enforcement.

- Increase the public's perceptions of the dangers of aggressive driving, including aggressive driving in general and specific aggressive driving actions.

- Increase the public's perception of the probability of being ticketed for specific aggressive driving violations.

- Decrease the self-reported and observed incidence of aggressive driving actions.

- Decrease the number of crashes and injuries related to aggressive driving.

Rather than focusing generally on aggressive driving throughout the Milwaukee area, the Aggression Suppression Program adopted a more targeted approach. The enforcement and publicity efforts defined the following specific traffic offenses as aggressive driving:

- tailgating

- ramp meter violations

- high occupancy vehicle (HOV) lane violations

- stopping in an intersection, causing traffic "gridlock"

- excessive speed

- running a red light

- running a stop sign

- failing to use a turn signal

- failing to yield right-of-way

- shouting, beeping, flashing lights, making hand gestures, etc.

- weaving, cutting in and out of traffic

Following the program kick-off, the remainder of the six-month enforcement and awareness program was organized into a series of three-week campaigns, each addressing a specific offense, for example, speeding, tailgating. In addition, although the publicity and enforcement efforts were designed to change the attitudes and behaviors of the general driving public, these efforts also were targeted to specific locations and times. 
The program included the following elements:

- Training officers in the enforcement of aggressive driving offenses.

- Heightened enforcement directed at unsafe driving throughout the area, and also targeting specific aggressive driving offenses, specific locations, and times of heavy traffic congestion

- Testing innovative enforcement technologies to detect, apprehend, and convict violators.

- A public awareness campaign focusing on specific aggressive driving actions and coordinated with the enforcement program.

- A comprehensive evaluation of program effort and results.

A description of these program elements, the program coordination and management, the participating agencies, and the evaluation plan is provided below.

\section{Program Planning and Coordination}

The Aggression Suppression Program was coordinated by the City of Milwaukee Safety Commission, which also functions as the Safety Division of the Milwaukee Police Department. In addition to planning and coordinating the program, the Safety Commission was responsible for developing and implementing the public awareness efforts.

In recent years, Milwaukee City and County have conducted a number of special programs to enforce traffic violations, including speeding and hit and run. In addition, the Milwaukee Police Department in fall 1996 implemented a "quality of life" enforcement program; this program focused particularly on speeding and other traffic offenses. The number of citations issued to drivers by the Milwaukee Police Department for moving traffic violations increased from 79,008 in 1995 to 148,867 in 1997, and then declined to 130,799 in 1998.

The involvement of the Milwaukee County Law Enforcement Executives Association (MCLEEA) in the Aggression Suppression Program ensured that the program would be implemented countywide. MCLEEA member agencies include the City of Milwaukee Police Department, the Milwaukee County Office of the Sheriff, and the 18 suburban law enforcement agencies in the County. All twenty MCLEEA member agencies participated in both the publicity and the enforcement efforts. Five of these agencies received funding to conduct special enforcement; these agencies included the Milwaukee County Office of the Sheriff and the law enforcement agencies of the cities of Milwaukee, Glendale, Wauwatosa, and West Allis.

An advisory committee assisted in planning and implementing the program and met monthly during the six-month enforcement period to help coordinate and monitor the project. The committee included representatives of the five enforcement agencies that received funding; the Bureau of Transportation Safety and the Traffic Operations Center, Wisconsin Department of Transportation; and the Infrastructure Service Division, Department of Public Works, City of Milwaukee. The Advisory Committee also included a representative from the 
evaluator Preusser Research Group, Inc. Additional partners included the Wisconsin AAA, County and municipal judges, the City of Milwaukee attorney, the District Attorney, and the Court Commissioner.

\section{Public Awareness Program}

A key component of the Aggression Suppression Program was publicity about the nature of the aggressive driving problem and the special enforcement efforts. The public awareness program consisted primarily of the distribution of various public awareness materials and earned media coverage, that is, news coverage "earned" by making news. A special effort was made to secure coverage by the four local television stations. The federal demonstration grant funds did not permit the purchase of media time, since it is unlikely that other law enforcement agencies attempting to replicate the strategies successfully used in Milwaukee would have funds to purchase media.

The publicity began with a press event in October 1998, announcing the selection of Milwaukee as the first aggressive driving program demonstration site. The event involved the U.S. Secretary of Transportation, the Mayor and Chief of Police from the City of Milwaukee, the County Executive and Sheriff of Milwaukee County, and a number of other local officials and dignitaries.

The publicity plan for the Aggression Suppression program, provided in Table 2.1, included 13 media events. Local and national enforcement representatives and highway safety officials attended the kick-off press conference on March 30, launching the special enforcement efforts. At the event, the logo and name of the program were introduced. Enhanced enforcement activities also were announced, including the use of in-vehicle video cameras, plainclothes law enforcement observers at targeted intersections, unconventional patrol vehicles, and magnetic "Aggressive Driving Patrol" signs placed on patrol vehicles during traffic stops. Reporters were given an opportunity to view the mobile video cameras and to film a special enforcement effort at a nearby intersection. Reporters also were encouraged to ride along with sheriff's patrol squads to observe aggressive driving behaviors on the freeways and to witness aggressive driving enforcement. All four local television stations, the major daily newspaper, a suburban weekly newspaper, and two radio stations attended the press conference. Extensive coverage of the kick-off occurred in all the media. Also on March 30, copies of the press release and other materials were mailed to 400 employers and to area high schools, driver education schools, and school bus companies.

In early April publicity focused on two special enforcement initiatives designed to increase the flow of traffic. On April 5 it was announced that Gridlock Enforcement would begin to target motorists who stopped in the intersection during the green light or entered the intersection after the traffic light had turned yellow or red. On April 12 it was announced that Ramp Meter Enforcement would begin; this enforcement targeted drivers who failed to stop for a red light at a ramp meter or who used the car pool lane when driving alone. 


\begin{tabular}{|c|c|}
\hline GGGRES & $\begin{array}{c}\text { Table } 2.1 \\
\text { Aggression Suppression Publicity Plan to } \\
\text { Support Enforcement Phase } \\
\text { April-September } 1999\end{array}$ \\
\hline March 30 & Campaign Kick-off; Enforcement Begins \\
\hline April 5 & Gridlock Enforcement (Blocking the Intersection) Announced \\
\hline April 12 & Highway Ramp Meter Enforcement Announced \\
\hline \multirow[t]{3}{*}{ April $19-$ May 9} & $\begin{array}{l}\text { Milwaukee County Law Enforcement Executives Association hosts } \\
\text { first press conference; three-week patrols announced. }\end{array}$ \\
\hline & $\begin{array}{l}\text { Space Patrol: Police will pay special attention to drivers not } \\
\text { leaving enough space between vehicles, tailgating. }\end{array}$ \\
\hline & $\begin{array}{l}\text { The use of laser technology to measure the distance between cars is } \\
\text { unveiled. }\end{array}$ \\
\hline April 26 & Hotline Announced \\
\hline May 3 & Trained Citizen Observer Class Announced \\
\hline May 10 - May 31 & $\begin{array}{l}\text { Angel Patrol: Police will look for drivers driving faster than their } \\
\text { guardian angel can fly over the posted speed limit. }\end{array}$ \\
\hline May 31 - June 21 & $\begin{array}{l}\text { Kindergarten Patrol: Police will watch for drivers who did not } \\
\text { learn in kindergarten that red means stop. }\end{array}$ \\
\hline June 21 - July 12 & $\begin{array}{l}\text { Flasher Patrol: Police will watch for drivers not using their } \\
\text { flashers or turn signals when turning or switching lanes. }\end{array}$ \\
\hline July 12 - August 2 & $\begin{array}{l}\text { Courtesy Patrol: Police will pay particular attention to } \\
\text { discourteous drivers who think "me first" and fail to yield the } \\
\text { right-of-way. }\end{array}$ \\
\hline August 2 - August 23 & $\begin{array}{l}\text { Rude Attitude Patrol (a.k.a. Bird Watchers Patrol): Police will } \\
\text { watch for drivers who have lost personal control, yelling, beeping, } \\
\text { flashing lights, giving gestures, tailgating, etc. }\end{array}$ \\
\hline August $23-$ September 13 & $\begin{array}{l}\text { Basket Patrol: Police will look for drivers who like to weave, } \\
\text { those who cut in and out, and speeding as they weave their way } \\
\text { through traffic. }\end{array}$ \\
\hline September 13 - September 30 & $\begin{array}{l}\text { Time Management Patrol: Police will watch for those people who } \\
\text { don't manage time well and speed to try to make up for it. }\end{array}$ \\
\hline
\end{tabular}


A key feature of the Aggression Suppression publicity plan was a series of "subtheme" campaigns, each addressing a particular type of aggressive driving. Thus, beginning on April 19, the publicity plan called for a series of eight public awareness campaigns, each lasting three weeks and addressing an aggressive driving behavior that was emphasized by the enforcement patrols (Table 2.1). An attention-getting descriptive slogan was associated with each theme. For example, the campaign to encourage the use of flashers or turn signals was entitled the "Flasher Patrol," and the "Basket Patrol" featured drivers who weave, cut in and out of traffic, and speed. Each campaign was launched by a press conference hosted by one of the participating enforcement agencies.

Extensive earned media coverage occurred throughout the six-month program. In general, television and radio coverage was more extensive than coverage by the print media. Each press conference to announce one of the special patrols was attended by three or four television stations and was often attended by one or more radio stations. The press releases featured the special enforcement equipment described below. The publicity highlighted the roadway corridors and intersections that were targeted by the enforcement efforts, also described below.

The aggressive driving patrols were frequently the subject of radio call-in talk shows. In particular, the Rude Attitude Patrol generated extensive press coverage after one radio station questioned whether enforcement agencies were exceeding their authority. The radio station interviewed an attorney about whether drivers' constitutional rights were being violated. This concern was precipitated by the program's press announcement, which indicated that enforcement agencies would be "watching those who lose personal control by yelling, beeping, flashing lights, giving gestures, tailgating, etc." Additional press conferences were held to explain that although these behaviors might not constitute traffic violations, the behaviors might draw officers' attention to potential traffic violations, such as speeding or running a red light.

Overall, it was believed that the Aggression Suppression Program succeeded in sustaining media interest by using novel and different sub-campaign themes, involving multiple enforcement agencies, staging novel media events (for example, patrol ride-alongs), and drawing the media's attention to innovative enforcement technologies and strategies.

The press events were coordinated with additional mailings to businesses and schools and the distribution of bumper stickers, posters, flyers, and other publicity materials. Posters for each special patrol and copies of the press announcement were sent to participating law enforcement departments and to all high school driver education teachers and 450 businesses in the Milwaukee area. As part of the Aggression Suppression Program, the City of Milwaukee Police Department developed a "Distance between Cars Laser" poster and card, a "Gridlock" flyer, an "Aggression Suppression" flyer, an "Aggression Suppression - Keep Cool, Drive Courteously" sticker and poster, and a citation book-sized informational card for officers' reference as they worked this project. The card contained the statutory reference for each offense that is often considered aggressive driving.

Additional publicity materials were provided by the State's "Let It Ride" program, which was implemented by the Wisconsin Bureau of Transportation Safety through its Task Force on Road Rage. These materials included a "Let It Ride, Courtesy Rules the Road" booklet and an "Aggressive Driver" flyer, which was distributed by officers to drivers issued 
tickets for aggressive driving violations. In some cases, the Aggression Suppression logo was placed on the State's materials. The State's "Let It Ride" public service announcement was distributed to television stations in the Milwaukee area and shown at 120 movie theaters throughout the State. In September 1999, the Bureau of Transportation Safety distributed to high schools a videotape on aggressive driving, which used the same theme as the "Let It Ride" public service announcement. The Aggressive Driving Program sent copies of this videotape to businesses in the Milwaukee area.

The publicity program also included the following:

- Magnetic "Aggressive Driving Patrol" signs placed on the rear of patrol vehicles each time a traffic stop was made.

- Replication of the National Highway Traffic Safety Administration's "Aggressive Drivers - Who Are They?" handout and the "I Stop for Red Lights" bumper sticker produced by the Federal Highway Administration.

- Release by AAA Wisconsin of public service announcements on aggressive driving (What If, Road War Classics, Yellow Light/Red Light, Simple Approach) to all Milwaukee media stations the week of the Aggression Suppression kick-off and airing of the announcements throughout the program.

The original publicity plan called for the establishment of an aggressive driving hotline. However, this proved unfeasible because the cell phone companies required indemnification. There also were concerns that there would be liability to the City or County if the service were discontinued at some point. The use of citizen observers was deemed to have limited success, due to several factors. The observers were recruited from the police auxiliaries, but the concept gradually lost the support of the law enforcement agencies. The agencies were concerned that they would be burdened by a large volume of reports and that the citizen observers would take action on their own and possible endanger themselves. Only two referrals were received from the observers, both for violations occurring on the freeway. The program organizers hypothesized that the citizen observers were either afraid to report violators or apathetic. Despite these problems, however, it is possible that the publicity about the observers and the hotline had a general deterrent effect on drivers by raising the public's perception that enforcement of aggressive driving offenses had increased.

An Aggression Suppression logo was created and placed on materials, but it was not ready in time for some of the earlier materials.

\section{Enforcement Program}

All 20 enforcement agencies in the City and County participated in the enforcement component of the program. The primary agencies involved in the enforcement program were the City of Milwaukee Police Department, patrolling Milwaukee's city streets, and the Milwaukee County Office of the Sheriff, patrolling the freeway and interstate roadways. Both agencies received project funding for overtime enforcement. 
The law enforcement agencies of the surrounding suburban cities were encouraged to participate to the extent possible, with support from the Wisconsin Highway Safety Office ("Section 402") funds. Wauwatosa, Glendale, and West Allis received Section 402 funding for increased enforcement of aggressive driving offenses, as part of an aggressive driving pilot project coordinated by the Wisconsin Bureau of Transportation Safety. From May to September 1999, these three agencies undertook special enforcement of aggressive driving offenses and participated in the publicity efforts. During this period, the special enforcement hours totaled 288 hours in Wauwatosa, 140 hours in Glendale, and an estimated 800 hours in West Allis.

Fifteen additional suburban law enforcement agencies participated voluntarily in the program without special funding. All publicity and enforcement materials were provided to these 15 agencies, as well as to West Allis, Wauwatosa, and Glendale, and all these agencies participated in the publicity events.

The special enforcement efforts of the Office of the Sheriff were coordinated by its Traffic Division and focused on the particular traffic violations designated by the program as aggressive (tailgating, ramp meter violations, high occupancy vehicle (HOV) violations, stopping in an intersection, excessive speed, running a red light, running a stop sign, failing to use a turn signal, failing to yield right-of-way, cutting in and out of traffic). For the purposes of the program, the Office of the Sheriff defined speeding as "aggressive driving" if the vehicle speed exceeded the posted speed limit by $20 \mathrm{MPH}$ or more. In all, 1,455 overtime hours were dedicated to aggressive driving enforcement and funded through the NHTSA grant. An additional 760 hours of dedicated aggressive enforcement were funded through the matching efforts of the Office of the Sheriff.

The enhanced enforcement efforts of the City of Milwaukee Police Department also focused on the particular offenses defined as aggressive. The program was coordinated through the Department's Special Operations Bureau Motorcycle/Traffic Enforcement section. Under the NHTSA grant, 5,700 patrol hours and 900 administrative and supervisory hours were funded.

In general, exceeding the speed limit by at least $15 \mathrm{MPH}$ was considered "aggressive" by the City Police Department, although the Department recognized the difficulty of setting a speed threshold that would be appropriate for all types of city streets. Increased enforcement of unsafe driving offenses occurred throughout the City, and intensified enforcement also was targeted toward eight specific roadway corridors and seven signalized intersections (Table 2.2). Some, but not all, of the targeted intersections were located on the targeted corridors.

The selection of the targeted corridors was based on a review of historical crash data and citation data for the City of Milwaukee. The City's Infrastructure Services Division, Department of Public Works, provided detailed information on the number and characteristics of crashes occurring at various locations, including information on the contributory crash factors. The targeted corridors were located on high-volume arterial roadways. The criterion for selection was 20 or more crashes occurring over the prior three years and involving the following factors: excessive speed, speed too fast for conditions, failing to yield right-of-way, following too closely, disregarding a traffic signal or sign, and 
improper overtaking. Historical crash data also provided the basis for the selection of the targeted intersections. Each of the selected intersections had at least 35 aggressive drivingrelated crashes in the prior three years.

\begin{tabular}{|l|} 
Table 2.2 \\
Aggression Suppression Program \\
Targeted Enforcement Locations in the \\
City of Milwaukee
\end{tabular}

The enforcement effort included the following innovative strategies:

- Enforcement Targeted to Times and Locations: With the assistance of Milwaukee's Traffic Operations Center, enforcement was targeted to locations and times of heavy traffic congestion, during morning and evening rush hours, and during scheduled events such as the State Fair.

- In-car Video Cameras in Patrol Vehicles and Unconventional Vehicles: Video cameras, purchased with project funds, were mounted in the front and rear of unmarked and marked vehicles used by the Office of the Sheriff and unmarked vehicles used by the City of Milwaukee patrols squads. Unmarked unconventional vehicles used by the City of Milwaukee included a mini van, a Cadillac, an older model Toyota, and a motorcycle. An officer following on motorcycle made the traffic stops. The Office of the Sheriff placed video 
cameras in marked patrol vehicles and in unmarked Chevy Luminas equipped with lights and sirens. Uniformed Sheriff's Deputies drove these vehicles and made their own stops.

The State Patrol trained an officer from the Office of the Sheriff and an officer from the Milwaukee Police Department in the use of the video cameras; these officers then trained other officers.

- Enforcement at Intersections: "Spotters" (officers in plainclothes) were placed at intersections in the City of Milwaukee to detect red light-running, failure to use turn signals, etc. The spotters radioed information on violators to motorcycle officers placed in downstream traffic. Later in the program, motorcycle officers were stationed on corners to detect and apprehend violators.

Officers stationed on street corners of targeted intersections served as "Gridlock Patrols" to apprehend drivers stopped in intersections.

- Laser Speed Detection Devices: City and Sheriff officers used laser speed detection devices (Laser Technology Incorporated LTI 20-20 Ultra-Lyte LR Lasers), purchased with program funds, to apprehend speeders.

- Distance between Cars Technology: Sheriff and City officers tested laser devices approved for speed detection (on the Consumer Products Lists (CPL)), but also equipped with LTI technology to measure the distance between cars (DBC). The test assessed the usefulness of the DBC technology in detecting drivers who are following too closely. The technology could not be used to write citations, since the device with this additional technological feature had not been through testing standards and minimum performance specifications for police laser speed-measuring devices. (NHTSA, in conjunction with the International Association of Chiefs of Police and the Law Enforcement Standards Laboratory of the National Institute of Standards and Technology (NIST), develops testing protocols and performance standards for police speed-measuring devices. Approved devices are published on a CPL.)

- Magnetic Vehicle Signs: Magnetic "Aggressive Driving Patrol" signs were placed on the rear of patrol vehicles when a traffic stop was made. This alerted passing motorists that a driver had been apprehended for an aggressive driving violation. The signs were used on patrol vehicles of the City of Milwaukee, the Sheriff, and suburban law enforcement agencies.

- Highway Ramp Enforcement: Sheriff's officers were stationed at highway ramps during rush hours and at other times to enforce High Occupancy Vehicle (HOV) lane and ramp meter violations.

- Distribution of Educational Booklet to Motorists: Officers of participating agencies gave an educational booklet on aggressive driving to persons issued traffic citations. 
- Electronic Speed Display Boards: Electronic display boards, posted at various locations throughout the City and County, displayed motorists' traveling speeds and indicated whether a motorist was exceeding the posted speed limit. The boards also displayed aggressive driving messages. The signs were used with and without an officer working in downstream traffic.

- Roll Call Videotape and Announcements: A roll call videotape on the enforcement of aggressive driving offenses was produced by the Wisconsin Bureau of Transportation Safety in cooperation with the Milwaukee Police Department and the Office of the Sheriff; the videotape was provided to all agencies in the County when the program was initiated. Roll call announcements also were made throughout the program to describe each specific campaign and encourage enforcement of aggressive driving offenses by all officers.

- Informational Card for Officers: The City of Milwaukee Police Department developed a citation book-sized card for officers to reference as they worked this project. The card contained the statutory reference for each offense that is often considered aggressive driving.

- Citation Checkbox: Officers were trained to place a notation of "AD" on citations when they cited for a violation they viewed as aggressive. This helped agencies track these violations and helped differentiate between like offenses. For example, based on officer observation, one improper lane change may be a routine violation and another may be considered aggressive.

\section{Evaluation}

The Preusser Research Group (PRG), Inc., conducted an evaluation of the Aggression Suppression Program. A process evaluation addressed the following questions: 1) What were the key elements of the program? 2) Was the program implemented fully and in accordance with the plan, that is, did the level of publicity and enforcement of aggressive driving increase? 3) What elements of the program were most successful, and which were least successful? An outcome evaluation examined whether there were positive changes in drivers' awareness, knowledge, and perceived risk related to aggressive driving; aggressive driving behaviors; and crashes. In addition, as the first comprehensive evaluation of a community aggressive driving program, the evaluation was intended to develop and test methods to assess future aggressive driving programs.

In conducting the process evaluation, a review was made of planning documents and official reports to NHTSA, publicity materials, and files of press clippings. To help prepare a full description of the program activities and assess the relative success of different program elements, discussions were held with the Project Manager and key officers in the Office of the Sheriff and Milwaukee Police Department. 
The following types of data were either obtained or generated for the evaluation:

1) Data on the numbers and types of citations issued by the Office of the Sheriff and the Milwaukee Police Department for the six months of the program and for a six-month baseline period.

2) Data on self-reported attitudes, perceptions, and behaviors related to aggressive driving, collected through self-administered surveys of a representative sample of Milwaukee drivers, conducted prior to, during, and after the program.

3) Observational data on driving behaviors, collected by videotaping traffic during pre-program, mid-program, and post-program periods at target and comparison intersections and on a limited access highway.

4) Data on the numbers and characteristics of crashes occurring during the program and for a baseline period for the entire City and for the eight roadway corridors targeted by the program and eight comparison corridors. 


\section{CHAPTER 3: RESULTS}

\section{Program Implementation}

Based on a review of program documentation and discussions with the Project Manager and participating enforcement agencies, the Aggression Suppression Program was implemented fully and in accordance with the plan. As a result of 12 media events and other public awareness initiatives, the program generated a large volume of publicity, especially earned media coverage. The program appeared to be successful in "selling" the story to the media, especially in the initial stages of the program. Given the absence of paid media time and the fact that Milwaukee is a large and complex media market, however, it must be acknowledged that the program was not able to "saturate" the media with its message. As previously noted, only two elements of the planned publicity were not implemented as anticipated. The establishment of an aggressive driving hotline proved unfeasible because of concern for liability for the government and the cell phone companies. In addition, the use of citizen observers had limited success; only two referrals were received from the observers.

The enforcement effort was successfully implemented. Participating agencies appeared to be enthusiastically involved in the program. All enforcement strategies were implemented as planned. Apart from delays in the receipt of some of the equipment, the technological aspects of the demonstration project were implemented as planned.

Finally, the coordination of the program also went according to plan. Monthly meetings of the Advisory Committee were well attended by representatives of the participating enforcement agencies and other partners.

\section{Enforcement Results}

The primary objective of the enforcement program was to conduct increased and highly visible enforcement of aggressive driving offenses, with a particular emphasis on nonspeed offenses. Detailed citation data were obtained from the Office of the Sheriff and the Milwaukee Police Department. When citations were compared for the six-month program period (April-September 1999) and the comparable six-month period in 1998, there were clear changes in the number and patterns of traffic citations issued for aggressive driving offenses. Officers in both agencies reported that aggressive driving violations became increasingly difficult to find as the program progressed.

\section{Office of the Sheriff}

Table 3.1 provides the numbers of citations issued for aggressive driving offenses by the Office of the Sheriff for April-September 1998 and 1999; these data include citations issued by the Traffic Division and by other divisions. There was a dramatic increase in the number of tickets issued for non-speed aggressive driving violations; non-speed citations increased by 55.3 percent, from 2,205 to 3,424 . Increases occurred for almost all specific offenses. For example, citations issued for failure to obey a sign or signal rose from 848 in 1998 to 1,507 in $1999(+77.7 \%)$ and citations issued for following too closely increased from 509 in 1998 to 885 in $1999(+73.9 \%)$. Citations for speeding violations declined by 6.2 
percent, from 12,647 in 1998 to 11,866 in 1999. Thus, citations for all aggressive driving offenses (including speed and non-speed violations) increased by 2.9 percent from 1998 to 1999. Citations for non-speed aggressive driving offenses represented a greater percentage of all aggressive driving citations in 1999 than in 1998 (22.4\% versus $14.8 \%)$.

\begin{tabular}{|c|c|c|c|}
\hline \multicolumn{4}{|c|}{$\begin{array}{c}\text { Table } 3.1 \\
\text { Citations for Aggressive Driving Offenses } \\
\text { All Divisions of the Milwaukee County Office of the Sheriff } \\
\text { April - September 1998, } 1999\end{array}$} \\
\hline & 1998 & 1999 & $\begin{array}{c}\text { Percent } \\
\text { Change } \\
1998 / 99\end{array}$ \\
\hline \multicolumn{4}{|l|}{ Non-Speed Violations } \\
\hline Deviation from Designated Lane & 289 & 370 & 28.0 \\
\hline $\begin{array}{l}\text { Failure to Obey Sign (including ramp } \\
\text { meter violations) }\end{array}$ & 848 & 1,507 & 77.7 \\
\hline Driving in Area not for Traffic & 2 & 4 & 100.0 \\
\hline Failure to Signal Turn & 2 & 17 & 750.0 \\
\hline Following Too Closely & 509 & 885 & 73.9 \\
\hline Reckless/Aggressive Driving & 51 & 69 & 35.3 \\
\hline Unsafe Cutting while Passing & 4 & 3 & -25.0 \\
\hline Unsafe Lane Deviation & 500 & 569 & 13.8 \\
\hline Non-Speed Sub-Total & 2,205 & 3,424 & 55.3 \\
\hline \multicolumn{4}{|l|}{ Speeding Violations } \\
\hline Excessive Speed & 11,994 & 11,015 & -8.2 \\
\hline Imprudent Speed & 592 & 738 & 24.7 \\
\hline Too Fast for Conditions & 61 & 113 & 85.2 \\
\hline Speed Sub-Total & 12,647 & 11,866 & -6.2 \\
\hline Total Aggressive Driving Offenses & 14,852 & 15,290 & 2.9 \\
\hline Percent Non-Speed Citations & 14.8 & 22.4 & \\
\hline
\end{tabular}


Table 3.2 provides April-September 1998 and 1999 data on citations for moving violations issued by the Traffic Division of the Office of the Sheriff. (Note that these data differ from the data presented in Table 3.1, which include citations issued by other divisions in addition to the Traffic Division.) The data provided in Table 3.2 indicate decreases in 1999 , compared with 1998 , for citations for speeding $(-14.5 \%)$, operating while intoxicated $(-0.8 \%)$, and driving with a revoked or suspended license $(-10.5 \%)$. Citations for all other moving violations increased by 21.5 percent.

\begin{tabular}{|l|c|c|c|}
\hline \multicolumn{4}{|c|}{ Table 3.2 } \\
Citations for Moving Violations \\
Traffic Division, Milwaukee County Office of the Sheriff \\
April-September 1998, 1999 \\
\hline & 1998 & $\mathbf{1 9 9 9}$ & $\begin{array}{r}\text { Percent } \\
\text { Change }\end{array}$ \\
\hline Speeding & 11,969 & 10,229 & -14.5 \\
\hline Operating while Intoxicated & 360 & 357 & -0.8 \\
\hline $\begin{array}{l}\text { Operating after Revoked/ } \\
\text { Suspended License }\end{array}$ & 1,471 & 1,317 & -10.5 \\
\hline Other Moving Violations & 4,495 & 5,463 & 21.5 \\
\hline Non-moving Violations & 1,419 & 1,430 & 0.8 \\
\hline Seat Belt Violations & 660 & 792 & 20.0 \\
\hline & & & \\
\hline \multicolumn{1}{|c|}{ Total } & $\mathbf{2 0 , 3 7 4}$ & $\mathbf{1 9 , 5 8 8}$ & $\mathbf{- 3 . 9}$ \\
\hline \% Other Moving Violations & $\mathbf{2 2 . 1}$ & $\mathbf{2 7 . 8}$ & \\
\hline
\end{tabular}


Throughout the program, the Traffic Division, Office of the Sheriff, tracked the citations designated as "aggressive" driving violations. Table 3.3 provides the numbers of these citations issued during April-September 1999 by the grant-funded squads, the straighttime patrols representing the County's match, and the other regular patrols. The grant squads issued 2,102 tickets during the six-month program; the match squads issued 718 citations.

\begin{tabular}{|c|c|c|c|c|}
\hline \multicolumn{5}{|c|}{$\begin{array}{c}\text { Table } 3.3 \\
\text { Citations for Aggressive Driving Offenses } \\
\text { Traffic Division, Milwaukee County Office of the Sheriff } \\
\text { Grant Squads, County Match Squads, Regular Patrols } \\
\text { April-September } 1999\end{array}$} \\
\hline & $\begin{array}{c}\text { Grant } \\
\text { Squads }\end{array}$ & $\begin{array}{l}\text { County } \\
\text { Match } \\
\text { Squads }\end{array}$ & $\begin{array}{c}\text { Regular } \\
\text { Patrol }\end{array}$ & Total \\
\hline Failure to Obey Sign & 591 & 181 & 732 & 1,504 \\
\hline Unsafe Lane Deviation & 107 & 27 & 311 & 445 \\
\hline Speeding (20 MPH over) & 806 & 292 & 2,555 & 3,653 \\
\hline Following Too Closely & 217 & 58 & 558 & 833 \\
\hline Too Fast for Conditions & 2 & 0 & 76 & 78 \\
\hline Deviation from Designated Lane & 48 & 18 & 128 & 194 \\
\hline Driving in Area Not for Traffic & 4 & 2 & 32 & 38 \\
\hline Failure to Stop for Sign & 4 & 0 & 12 & 16 \\
\hline Reckless Driving & 5 & 1 & 47 & 53 \\
\hline Operating after Revocation/Suspension & 13 & 17 & 0 & 30 \\
\hline Operating while Intoxicated & 2 & 0 & 0 & 2 \\
\hline Miscellaneous & 303 & 122 & 60 & 485 \\
\hline Total & 2,102 & 718 & 4,511 & 7,331 \\
\hline
\end{tabular}




\section{City of Milwaukee}

The number of citations issued by the Milwaukee Police Department for non-speed aggressive driving offenses increased from 9,528 during April-September 1998 to 12,378 during April-September 1999, an increase of 29.9 percent (Table 3.4). For example, citations for disregarding an official sign or signal increased by 45.6 percent. Citations issued for speed violations increased by 2.7 percent. Thus, total citations for both speed and non-speed aggressive driving violations increased by 13.7 percent from 1998 to 1999 . Citations for most other types of moving violations, unrelated to aggressive driving, declined during this period.

As a percentage of citations for all moving violations, aggressive driving citations increased from 39.2 percent in 1998 to 44.0 percent in 1999, while non-speed aggressive driving citations increased from 15.9 percent to 20.4 percent.

Table 3.4

Citations for Moving Violations

City of Milwaukee Police Department April-September 1998, 1999

\begin{tabular}{|c|c|c|c|}
\hline & 1998 & 1999 & $\begin{array}{c}\text { Percent } \\
\text { Change } \\
1998 / 99\end{array}$ \\
\hline Deviating in Traffic & 845 & 830 & -1.8 \\
\hline Disregarding Official Sign/Signal & 4,899 & 7,135 & 45.6 \\
\hline Failure to Yield Right-of-way & 1,419 & 1,471 & 3.7 \\
\hline Other Moving Violations & 2,215 & 2,739 & 23.7 \\
\hline Reckless Driving & 150 & 203 & 35.3 \\
\hline Total Non-Speed Aggressive & 9,528 & 12,378 & 29.9 \\
\hline Speeding & 13,994 & 14,376 & 2.7 \\
\hline Total Aggressive Citations & 23,522 & 26,754 & 13.7 \\
\hline Operating while Intoxicated & 1,702 & 1,396 & -18.0 \\
\hline Auto License Law & 8,480 & 9,319 & 9.9 \\
\hline Driver License Law & 19,313 & 16,610 & -14.0 \\
\hline Seat Belt Violations & 4,832 & 4,848 & .3 \\
\hline Failure to Turn in Plates & 2,215 & 1,832 & -17.3 \\
\hline Total Moving Violations & 60,064 & 60,759 & 1.2 \\
\hline Percent Aggressive & 39.2 & 44.0 & \\
\hline Percent Non-Speed Aggressive & 15.9 & 20.4 & \\
\hline
\end{tabular}


Table 3.5 provides counts of citations issued for aggressive driving offenses by the City's grant-funded patrols and the non-grant patrols. The grant patrols issued 4,405 citations during the six-month grant period. More than half these citations were issued for disobeying a stop sign or signal. A review of the citations by the grant-funded officers indicated that the large majority of tickets were issued along the targeted corridors and/or at the targeted intersections.

\begin{tabular}{|c|c|c|}
\hline \multicolumn{3}{|c|}{$\begin{array}{l}\text { Table 3.5: Citations Issued for } \\
\text { Aggressive Driving Offenses } \\
\text { City of Milwaukee Police Department } \\
\text { Grant Patrols and Non-grant Patrols } \\
\text { April-September } 1999\end{array}$} \\
\hline & $\begin{array}{c}\text { Grant } \\
\text { Patrols* }\end{array}$ & $\begin{array}{l}\text { Non-grant } \\
\text { Patrols }\end{array}$ \\
\hline Disobeying Stop Sign/Signal & 2,216 & 4,919 \\
\hline Speeding/Racing & 1,780 & 12,174 \\
\hline Illegal Turn & 101 & 390 \\
\hline Failure to Yield Right-of-Way & 98 & 1,373 \\
\hline Lane Deviation & 56 & 886 \\
\hline Failure to Signal & 30 & 23 \\
\hline Illegal Use of Horn & 15 & 8 \\
\hline Following Too Closely & 10 & 260 \\
\hline Illegal Passing & 10 & 65 \\
\hline Driving Wrong Side & 4 & 117 \\
\hline Reckless Driving & 4 & 199 \\
\hline Failure to Stop at Crossing & 3 & 3 \\
\hline Illegal Backing & 1 & 91 \\
\hline Other & 77 & 69 \\
\hline Total & 4,405 & 20,577 \\
\hline \multicolumn{3}{|c|}{$\begin{array}{l}\text { *Note: Grant Patrol Citations do not include } 2,397 \text { citations for } \\
\text { traffic violations that were not judged to be aggressive } \\
\text { driving. }\end{array}$} \\
\hline
\end{tabular}




\section{$\underline{\text { Suburban City Agencies }}$}

Three suburban city law enforcement agencies undertook State-funded aggressive driving programs in conjunction with the efforts of the City of Milwaukee Police Department and the Office of the Sheriff. Although no historical data were available for comparison, these agencies reported the numbers of citations for aggressive driving offenses that were issued by the grant-funded patrols during their project period, May-September 1999. It should be noted that seat belt and child safety seat enforcement was a focus of these grant, as well as aggressive driving violations.

Most of the special enforcement undertaken by the City of Wauwatosa Police Department was conducted on the feeder streets leading to the Milwaukee County freeway systems. The department issued a total of 244 citations and 123 warnings for aggressive driving offenses and seat belt/child restraint offenses.

The City of West Allis Police Department reported that it made one enforcement contact every 22 minutes. The agency's special enforcement occurred primarily on Friday nights and during rush hours, when drivers were most likely to speed and engage in other aggressive behaviors. From May to September, 1,217 citations and warnings were issued.

The City of Glendale Police Department issued 293 citations for aggressive driving offenses and seat belt/child restraint violations.

\section{Agencies' Assessment of Enforcement Efforts}

According to the Project Manager and the key officers involved in the Aggression Suppression Program from the City of Milwaukee Police Department and the Office of the Sheriff, the program was successful in securing buy-in from the general traffic patrols. The City's motorcycle traffic officers and officers in the Traffic Division, Office of the Sheriff, demonstrated enthusiastic support for the program. Factors believed to contribute to this success were the roll call videotape, which provided a good introduction to the program, and the rotating focus among the enforcement of different violations, which helped sustain officers' interest in the program. The agencies also found the educational flyer on aggressive driving to be useful. It served as a reminder for officers to concentrate on aggressive driving violations and was given to violators issued tickets. In addition, agencies were positive about the use of the magnetic vehicle "Aggressive Diving Patrols" signs. When the signs were first introduced, some were blown off the vehicles when officers on the freeways forgot to remove the signs before driving off at high speeds.

Enforcement agencies reported that the use of electronic speed display boards helped raise awareness of the increased enforcement, especially when the boards were used in conjunction with officers using either laser or radar speed equipment. It also was noted that to achieve maximum effectiveness, the board should be placed at a new location after a few days. The LTI 20-20 Ultra-Lyte laser speed equipment was well received by motorcycle officers and other officers working on the grant. The units proved to be light and easy to use. Because they are battery operated, cumbersome cords are eliminated. Officers reported that the lighter units resulted in less fatigue, and thus, increased use. 
Officers were less enthusiastic about the LTI laser distance-between-cars (DBC) feature of the laser guns. The feature was designed to calculate the distance between two vehicles traveling in the same direction, one in front of the other, and to aid the officer in enforcement of citations for tailgating. The Aggression Suppression Program had not intended to use the DBC equipment as a basis for writing citations; rather, the program provided an opportunity to conduct a field test to assess the feasibility of using the equipment for enforcement. Program staff met with prosecutors and judges to explain the equipment, but the DBC evidence was not used as part of officers' testimony in court. Officers reported that the $\mathrm{DBC}$ equipment had considerable value in convincing motorists that they had, in fact, been tailgating. It also was believed that publicity about the equipment had a general deterrent effect, although delays in receiving the equipment meant that the announcement of its use occurred later than planned.

However, despite its obvious public relations value, officers found the DBC equipment to be an impractical way to measure tailgating. Officers found it difficult to accomplish the needed quick and accurate aiming of the laser in heavy traffic. In addition, the entire procedure was complex. To achieve accurate measurement of the distance between two vehicles, the officer must first aim at the front of the first vehicle and press the trigger of the unit. Then the officer must quickly aim at the front of the second vehicle and press the trigger to receive the measure of distance, expressed in either feet or seconds. Because the reported distance is measured between the fronts of the vehicles, the officers must mentally estimate and subtract the length of the front vehicle from the reported distance in order to obtain the length of the gap between the two vehicles. In addition to the need for officers to develop skill in using the DBC equipment, its use required a team of two officers - one officer to operate the equipment and a second officer to apprehend the violator.

The three suburban law enforcement agencies reported that the State-funded program in aggressive driving was well received by their agencies. Two of these agencies noted that many of their roadways were under construction during the program period. Some special enforcement was targeted to these areas since the congestion and delays created by construction were believed to increase the occurrence of aggressive driving.

Although there were concerns prior to the program's inception that prosecutors and judges would have difficulty with the increase in non-speed citations, no such problems were reported. In addition, although it had been anticipated that a large number of criminal arrests would take place during enforcement of aggressive driving offenses, this was not the case.

\section{Driver Surveys}

Self-administered surveys were distributed to drivers obtaining or renewing their driver license at the five offices of the Wisconsin Department of Motor Vehicles (DMV) located within Milwaukee County. Since all drivers in Wisconsin must obtain or renew their license in person, this provided a feasible, low-cost method to survey a representative sample of Milwaukee drivers. 


\section{Method}

Three waves of surveys were conducted: one in March 1999, prior to the implementation of the program; one in July 1999, at the height of the program; and one in October 1999, soon after program activities had ended. DMV employees distributed the onepage survey to all persons either obtaining or renewing their license, and drivers were asked to deposit the completed survey in a "Completed Survey" box. Completed surveys totaled 1,417 in March, 1,538 in July, and 1,261 in October.

In order to limit the survey instrument to a single page, two versions of the instrument were prepared. Both versions gathered basic demographic information, including gender, age, race or ethnicity, and zip code. All survey respondents also were asked how many miles they expected to drive in the next year. Both versions of the instrument also included questions on the following topics:

- Whether Milwaukee drivers were ruder, more courteous, or about the same, when compared to the previous year.

- Perceived strictness of traffic law enforcement by enforcement agencies in Milwaukee County.

- Whether drivers had recently read, seen, or heard anything about police enforcement of traffic laws in Milwaukee, and if so, where.

The respondents also were queried about the nine specific aggressive driver actions addressed by the program and the associated publicity campaigns, including. The survey items on the following topics were divided between the two versions of the instrument:

- How often these aggressive driver actions cause problems on area roadways.

- How often respondents engaged in each of the specific actions in the last 30 days.

- Perceived chances of getting a ticket for the nine aggressive actions.

- Whether respondents had recently read, seen, or heard anything about the 10 specific program themes; the State's "Let It Ride" campaign; or the national campaign, "Buckle Up America."

Responses were compared between the pre-program and mid-program surveys, and between the pre-program and post-program surveys. Statistical significance was based on the chi-square test, with $\mathrm{p}<0.01$ defined as significant. Responses also were examined by respondent characteristics, but no consistent patterns were identified.

\section{$\underline{\text { Results }}$}

For all three waves of the survey combined, 52.0 percent of the respondents were male. About one-third were less than 25 years old, one-third were 26-39. years old, and onethird were 40 years or older. More than half the respondents were non-Hispanic white $(56.5 \%), 31.1$ percent were non-Hispanic black, 6.7 percent were Hispanic, and the remaining respondents belonged to other ethnic or racial groups. 
About half the drivers surveyed in the pre-program survey $(48.3 \%)$ believed that Milwaukee drivers were ruder, when compared to a year ago; about half $(47.9 \%)$ believed that drivers were about the same, and only a few drivers (3.7\%) believed they were much more or more courteous. These results did not change significantly across the three waves of the survey.

The perceived strictness of general traffic enforcement was at a high level in the baseline survey. A large majority of respondents (70.5\%) reported that the County and City police departments enforce traffic laws either somewhat strictly or very strictly. This percentage declined to 63.3 percent in the mid-program survey $(\mathrm{p}<0.01)$. The percentage then rose in the post-program survey to 67.9 percent, which did not differ significantly from the pre-program percentage.

Although significant improvements did not occur in the perceived strictness of general law enforcement, drivers became more likely to believe that they would be ticketed for certain aggressive driving violations. The percentage of drivers who believed that they would always/nearly always receive a ticket for running a red light increased from 42.4 percent in the baseline survey to 49.1 percent in the mid-program survey $(p<0.01)$. Similarly, the percentage that believed they would always or nearly always receive a ticket for running a stop sign increased from 36.8 percent in the baseline survey to 45.4 percent in the mid-program survey $(p<0.01)$. Changes between the pre-program and post-program periods were not significant.

About 56 percent of the respondents in all three survey waves indicated that they had recently seen, read, or heard something about police enforcement of traffic laws in Milwaukee. With regard to the source of this information, in each survey about one in three of these respondents mentioned television, one in four mentioned newspapers, and one in six mentioned radio. Less than five percent mentioned posters, brochures, or checkpoints.

There was a significant increase between the baseline and mid-program surveys in the percentage of respondents who reported that they had recently seen, read, or heard anything about the campaign Rude Attitude Patrol ( $14.1 \%$ to $19.8 \%, \mathrm{p}<0.01)$, and about the State's "Let It Ride" campaign $(12.6 \%$ to $18.2 \%, \mathrm{p}<0.01)$. There were significant increases between the pre-program and post-program surveys in the percentage of respondents who had recently seen, read, or heard anything about the Space Patrol campaign (8.5\% to $13.3 \%, p<$ 0.01 ), the Courtesy Patrol campaign ( $16.0 \%$ to $25.0 \%, \mathrm{p}<0.01$ ), and the Rude Attitude Patrol campaign $(14.1 \%$ to $25.9 \%, \mathrm{p}<0.01)$. Although there were increases in the awareness of other campaign themes over the program period, these increases were not statistically significant. In each survey, driver awareness was highest for the "Buckle Up America" campaign, a national campaign to increase seatbelt use; about two-thirds of drivers in each survey had recently seen, read, or heard something about this campaign. It should be noted that the survey did not query drivers about their awareness of the overall campaign slogan, Aggression Suppression, since the choice of a slogan had not been finalized when the baseline survey was conduced. 
A set of questions focused on the extent to which drivers believed nine specific aggressive driving behaviors cause problems. As shown in Table 3.6, in the baseline survey, drivers believed that cutting off other drivers $(47.0 \%)$ or running a red light $(43.3 \%)$ was most likely to always/nearly always cause a problem.

\begin{tabular}{|l|c|}
\hline \multicolumn{2}{|c|}{ Table 3.6 } \\
Perceptions of the Problem Caused by \\
Aggressive Driving Behaviors \\
Survey of Milwaukee Drivers \\
March 1999 \\
\hline
\end{tabular}

More drivers in the mid-program survey than in the baseline survey believed that running a red light $(43.3 \%$ versus $51.2 \%, p<0.01)$ or driving through a stop sign $(41.3 \%$ versus $48.1 \%, \mathrm{p}<0.01$ ) was always/nearly always a problem. Fewer drivers in the midprogram survey believed that weaving in and out of traffic $(41.5 \%$ versus $34.2 \%, p<0.01)$ or exceeding the speed limit by at least $10 \mathrm{MPH}(33.5 \%$ versus $27.3 \%, \mathrm{p}<0.01)$ was always/nearly always a problem. There were no significant differences between the baseline and post-program responses for any of these reported behaviors.

A final set of questions focused on how often, if ever, drivers had engaged in each of these specific driving behaviors in the last 30 days. In the baseline survey, the following percentages of drivers reported that they had engaged in these behaviors on at least one occasion in the past 30 days: traveling at least $10 \mathrm{MPH}$ over the speed limit (67.4\%); failing to signal a turn or lane change $(47.0 \%)$; passing on the right $(32.4 \%)$; weaving in and out of traffic (28.9\%); tailgating (28.8\%); honking, flashing lights, gesturing $(27.5 \%)$; cutting off other drivers (22.8\%); driving through a stop sign (13.0\%); and running a red light $(11.9 \%)$. The reported frequency of these behaviors did not differ statistically across the three waves of the survey. 


\section{Observations of Driver Behavior}

Video cameras were used to record traffic at selected sites during a baseline period prior to the program, midway through the program, and after the program had ended. The videotapes were analyzed to derive counts of selected aggressive driving actions. Observations were conducted at selected signalized intersections and along a stretch of interstate highway.

\section{$\underline{\text { Red Light-Running }}$}

Observations were conducted at 20 signalized intersections to determine whether the extent of red light-running declined as a result of the program. Ten of the intersections were targeted by enforcement and public awareness efforts (i.e., target intersections), and 10 were matched comparison intersections.

The baseline observations were conducted from March 23 to April 8, the midprogram observations were conducted from July 15 to August 2, and the post-program observations were conducted from October 19 to December 9 . Observations were conducted during rush hours Monday-Friday, 6:45 a.m. - 8:45 a.m. and 3:30 p.m. - 5:30 p.m., with the cameras focused on the direction of heaviest traffic density. Half the matched pairs of target/comparison intersections were observed in the morning, and half were observed in the afternoon/evening. Thus, for each observational wave (baseline, mid-program, postprogram) a total of 40 hours of videotapes was generated, including 10 hours of morning observations and 10 hours of afternoon/evening observations for the target intersections, and 10 hours of morning and 10 hours of afternoon/evening observations for the comparison intersections.

One person coded all 120 hours of videotapes. The tapes were "blindly" coded; that is, the coder did not know whether the intersection was a target or comparison site. The order in which the tapes were coded ensured that baseline, mid-program, and post-program tapes were evenly dispersed throughout the coding period. The following coding procedures were established:

- The entire observation session was coded; thus, each signal change was observed throughout the two hours.

- A single code was assigned to each light cycle from the following alternative codes: 1) At least one vehicle "egregiously" ran a red light; 2) There were no egregious violations, but at least one vehicle "marginally" ran a red light; 3) All vehicles stopped on red; or 4) There were no opportunities for stopping at or running the red light.

- A violation was considered "egregious" if no part of the red light-running vehicle entered the intersection before the light turned red.

- A violation was considered "marginal" if the red light-running vehicle entered the intersection during the yellow light and the rear bumper had not passed the midpoint of the intersection by the time the light turned red.

- Traffic was coded as "stopped" if, during the yellow light, a vehicle entered into a three-car-length zone before the intersection and then stopped. 
- The light cycle was coded as "no opportunity" if there were no vehicles that ran the red light and no vehicles entered the three-car-length zone before the intersection during the yellow light.

- Any vehicle making a right turn was excluded, since there are special laws that pertain to making right turns on red.

- Vehicles making a left turn were included, with two exceptions. Vehicles using a left-turn-only lane were excluded, and vehicles turning left were excluded if the vehicle had already entered the intersection before the light turned yellow.

Due to extreme sun glare and the position of the camera, some tapes at some intersections could not be coded. Table 3.7 reports the results for the seven pairs of target/comparison intersections for which data were available for all three observational periods. With "no opportunity" light cycles excluded, the percentage of vehicles coded as stopped differed little between target and comparison sites or across waves; the percentage stopped ranged from 59.2 percent to 65.9 percent. However, the percent egregious red lightrunning declined at the target intersections from the pre-program period to the mid-program period (6.5\% versus $4.9 \%$ ), and the percent egregious red light-running increased at the comparison intersections ( $2.9 \%$ to $12.7 \%$ ). The percentage then increased from the midprogram period to the post-program period for the target intersections and was essentially unchanged at the comparison sites. 


\begin{tabular}{|c|c|c|c|c|}
\hline \multicolumn{5}{|c|}{$\begin{array}{c}\text { Table } 3.7 \\
\text { Milwaukee } \text { Aggression Suppression Program } \\
\text { Observed Red Light-Running Behavior } \\
\text { Target and Comparison Intersections } \\
\text { Pre-program, Mid-program, Post-program }\end{array}$} \\
\hline & $\begin{array}{c}\text { Percent } \\
\text { Egregious }\end{array}$ & $\begin{array}{c}\text { Percent } \\
\text { Marginal }\end{array}$ & $\begin{array}{l}\text { Percent } \\
\text { Stopped }\end{array}$ & $\begin{array}{c}\text { Percent } \\
\text { Total }\end{array}$ \\
\hline \multicolumn{5}{|l|}{ Pre-Program } \\
\hline Target Sites & 6.5 & 31.2 & 62.3 & $\begin{array}{c}100.0 \\
(n=220)\end{array}$ \\
\hline Comparison Sites & 2.9 & 31.2 & 65.9 & $\begin{array}{c}100.0 \\
(n=200)\end{array}$ \\
\hline \multicolumn{5}{|l|}{ Mid-Program } \\
\hline Target Sites & 4.9 & 34.0 & 61.1 & $\begin{array}{c}100.0 \\
(n=324)\end{array}$ \\
\hline Comparison Sites & 12.7 & 24.7 & 62.6 & $\begin{array}{c}100.0 \\
(n=173)\end{array}$ \\
\hline \multicolumn{5}{|l|}{ Post-Program } \\
\hline Target Sites & 10.3 & 27.0 & 62.7 & $\begin{array}{c}100.0 \\
(n=251)\end{array}$ \\
\hline Comparison Sites & 12.0 & 28.8 & 59.2 & $\begin{array}{c}100.0 \\
(n=202)\end{array}$ \\
\hline
\end{tabular}

Paired comparison tests were conducted to test the statistical significance of the changes in the percent of egregious red light-running between the pre-program, mid-program, and post-program periods. The first test examined these differences between the pre-program and mid-program periods, using paired data for the eight experimental intersections and the eight control intersections for which pre-program and mid-program data were available. For the experimental intersections, the percent egregious red-light running declined, on average, by -1.90 percentage points. For the control intersections, the percent egregious red-light running increased, on average, by +8.60 percentage points. The difference in these results was statistically significant $(\mathrm{t}=-3.466, \mathrm{p}<0.01, \mathrm{df}=7)$. A similar test was conducted for the differences between the pre-program and post-program periods, based on the seven pairs of intersections for which pre-program and post-program data were available. The experimental intersections experienced, on average, an increase of +3.73 percent points in egregious red light-running, and the control intersections experienced an increase of +9.06 percentage points, on average. The difference was not significant. 


\section{Highway Aggressive Driving}

A field test was conducted to assess the feasibility of identifying and coding highway aggressive driving behaviors, using videotaped observation data. Traffic was videotaped along a stretch of the U.S.-45/I-894 freeway, using one of the traffic monitoring cameras mounted at intervals along the Milwaukee freeway system and connected into the Wisconsin DOT Traffic Operations Center. Traffic moving in three lanes in one direction was videotaped on several days prior to the program, midway during the program, and after the program had ended. From the large number of videotapes produced, a balanced sample of tapes was selected for analysis; the sample included videotapes of morning and afternoon rush-hour traffic. In all, 18 hours of videotapes were selected for coding. It should be noted that although the target videotaped intersections were selected because they had been targeted by special enforcement efforts, the videotaped highway segment was not targeted for special enforcement, apart from the overall increased highway enforcement of aggressive driving offenses.

After a review of several hours of videotapes, it was determined that the coding procedures would focus on three types of aggressive driving actions, including spacing violations (tailgating and cutting into), weaving, and excessive speed. Each aggressive event also was given one of three severity codes: 1) egregious, i.e., clearly dangerous; 2) clear but not egregious; or 3) probable. A single person coded all 18 hours of videotapes, with the order of coding fixed to balance the number of tapes from each wave coded in the first, second, and final thirds of the coding activity.

The identification and coding of aggressive behaviors by drivers proved to be problematic in several respects. The camera's field of view permitted only a small segment of roadway to be filmed, and only about one-quarter mile could be effectively analyzed and coded. In general, only about 10 to 15 seconds of travel by a vehicle could be analyzed. Together with the heavy traffic congestion, this meant that a relatively small number of aggressive incidents could be observed. In addition, given the limited view afforded by the single, stationary camera, the heavy traffic congestion, and the short roadway segment, it was sometimes difficult to determine whether behaviors were "aggressive." For example, some types of aggressive driving involve a series of driving behaviors, which is difficult to detect in a few seconds of tape on a short stretch of roadway. Varying traffic volume, speed, and density also were of concern. As a result, the analysis of the sample of videotapes did not yield useful information.

\section{Crash Data}

The City of Milwaukee's Planning and Development Unit, Transportation Section, Infrastructure Services Division, Department of Public Works, provided baseline and program police-reported crash data. A special crash report, generated for the evaluation, provided the numbers of total, fatal, personal injury, and property-damage crashes during each of the months March-September for 1998 and 1999. Property-damage crashes were classified as "Property Damage +" or "Property Damage -" depending on whether or not the amount of property damage exceeded a reporting threshold. Detailed crash reports were generated for the entire City of Milwaukee, for each of the eight corridors targeted by the Milwaukee Police Department for intensified enforcement of aggressive driving offenses 
and for each of eight matched comparison corridors. To the extent possible, crashes were included if at least one involved vehicle was driving along the corridor road prior to the crash.

The analyses provided below were drawn from reports that provided monthly counts, by severity, of overall crashes, multiple-vehicle crashes, and crashes occurring at intersections. The number of crashes occurring during the program period, April-September 1999 , was compared to the number of crashes occurring during a baseline period, AprilSeptember 1998. Baseline/program changes in the number of citywide crashes, compared to the expected totals, were tested with the chi-square statistic. Changes in crashes occurring on the target and comparison corridors are also described. Since the target corridors were selected, in part, because they had a history of high-crash incidence, differences in crash patterns on the target and comparison corridors were not submitted to statistical tests.

A final set of analyses looked at crashes involving at least one driver aggressive action as a contributing crash factor. Aggressive driving actions included exceeding the speed limit, speed too fast for conditions, failing to yield right-of-way, following too closely, making an improper turn, disregarding a traffic control, and improper overtaking. 
As shown in Table 3.8, the overall number of crashes that occurred in the City of Milwaukee fell from 8,632 during the six-month period in 1998 to 8,217 in 1999 , a decline of 4.8 percent $(p<0.01)$. Crashes involving an injury or fatality declined by 6.6 percent, and the number of property-damage crashes decreased as well.

Total crashes for the eight target corridors combined declined by 12.3 percent from 1998 to 1999 . Personal injury and fatality crashes occurring on the target corridors declined by 11.3 percent, and property damage crashes also declined. The number of total crashes occurring along the comparison corridors declined by 2.2 percent, and personal injury/fatality crashes declined by 1.2 percent.

\begin{tabular}{|l|c|c|c|}
\hline \multicolumn{3}{|c|}{ Table 3.8 } \\
Police-reported Crashes \\
Target and Comparison Roadway Corridors and Citywide \\
City of Milwaukee \\
\hline \multicolumn{3}{|c|}{ April-September 1998, 1999 } \\
\hline Percent \\
\hline Change \\
\hline Target Corridors & $\mathbf{1 9 9 8}$ & 1999 & $1998 / 99$ \\
\hline Personal Injury or Fatality & 372 & 330 & -11.3 \\
\hline Property Damage + & 358 & 336 & -6.1 \\
\hline Property Damage - & 172 & 125 & -27.3 \\
\hline Total & $\mathbf{9 0 2}$ & $\mathbf{7 9 1}$ & -12.3 \\
\hline Comparison Corridors & & & \\
\hline Personal Injury or Fatality & 245 & 242 & -1.2 \\
\hline Property Damage + & 269 & 266 & -1.1 \\
\hline Property Damage - & 134 & 126 & -6.0 \\
\hline Total & $\mathbf{6 4 8}$ & $\mathbf{6 3 4}$ & $-\mathbf{- 2 . 2}$ \\
\hline Citywide & & & \\
\hline Personal Injury or Fatality & 2,915 & 2,723 & -6.6 \\
\hline Property Damage + & 3,887 & 3,831 & -1.4 \\
\hline Property Damage - & 1,830 & 1,663 & -9.1 \\
\hline Total & $\mathbf{8 , 6 3 2}$ & $\mathbf{8 , 2 1 7}$ & -4.8 \\
\hline
\end{tabular}


Table 3.9 provides information on crashes involving more than one vehicle. Citywide, multiple-vehicle crashes declined overall and within each category of severity; the 4.6 percent decline for all crashes represented a significant change $(p<0.01)$. Total multiplevehicle crashes occurring along the target corridors declined by 14.5 percent from 1998 to 1999. A smaller decline of 3.4 percent occurred for multiple-vehicle crashes along the comparison corridors. There were declines in the number of crashes in all severity categories for the target corridors; for the comparison corridors, smaller percentage declines occurred for personal injury/fatality crashes and non-reportable property damage crashes, while reportable property damage crashes increased slightly.

\begin{tabular}{|c|c|c|c|}
\hline \multicolumn{4}{|c|}{$\begin{array}{c}\text { Table } 3.9 \\
\text { Multiple-Vehicle Crashes } \\
\text { Target and Comparison Roadway Corridors } \\
\text { and Citywide } \\
\text { City of Milwaukee } \\
\text { April-September } 1998,1999\end{array}$} \\
\hline & 1998 & 1999 & $\begin{array}{c}\text { Percent } \\
\text { Change1 } \\
998 / 99 \\
\end{array}$ \\
\hline \multicolumn{4}{|l|}{ Target Corridors } \\
\hline Personal Injury or Fatality & 321 & 280 & -12.8 \\
\hline Property Damage + & 338 & 304 & -10.1 \\
\hline Property Damage - & 166 & 121 & -27.1 \\
\hline Total & 825 & 705 & -14.5 \\
\hline \multicolumn{4}{|l|}{ Comparison Corridors } \\
\hline Personal Injury or Fatality & 219 & 206 & -5.9 \\
\hline Property Damage + & 246 & 248 & 0.8 \\
\hline Property Damage - & 126 & 117 & -7.1 \\
\hline Total & 591 & 571 & -3.4 \\
\hline \multicolumn{4}{|l|}{ Citywide } \\
\hline Personal Injury or Fatality & 2,203 & 2,092 & -5.0 \\
\hline Property Damage + & 3,465 & 3,403 & -1.8 \\
\hline Property Damage - & 1,664 & 1,498 & -10.0 \\
\hline Total & 7,332 & 6,993 & -4.6 \\
\hline
\end{tabular}


Traffic crashes at intersections were of particular interest, since much of the special enforcement targeted red light-running, running a stop sign, and blocking an intersection. As shown in Table 3.10, a significant decline of 7.8 percent was observed for crashes at intersections citywide $(p<0.01)$. The number of total crashes occurring at intersections along the target corridors decreased by 16.3. Crashes at intersections decreased by 6.3 percent along the comparison corridors.

\begin{tabular}{|c|c|c|c|}
\hline \multicolumn{4}{|c|}{$\begin{array}{c}\text { Table } 3.10 \\
\text { Crashes at Intersections } \\
\text { Target and Comparison Roadway Corridors } \\
\text { and Citywide } \\
\text { City of Milwaukee } \\
\text { April-September 1998, } 1999\end{array}$} \\
\hline & 1998 & 1999 & $\begin{array}{c}\text { Percent } \\
\text { Change } \\
1998 / 99\end{array}$ \\
\hline \multicolumn{4}{|l|}{ Target Corridors } \\
\hline Personal Injury or Fatality & 254 & 215 & -15.4 \\
\hline Property Damage + & 230 & 200 & -13.0 \\
\hline Property Damage - & 61 & 41 & -32.8 \\
\hline Total & 545 & 456 & -16.3 \\
\hline \multicolumn{4}{|l|}{ Comparison Corridors } \\
\hline Personal Injury or Fatality & 170 & 161 & -5.3 \\
\hline Property Damage + & 165 & 152 & -7.9 \\
\hline Property Damage - & 45 & 43 & -4.4 \\
\hline Total & 380 & 356 & -6.3 \\
\hline \multicolumn{4}{|l|}{ Citywide } \\
\hline Personal Injury or Fatality & 1,761 & 1,623 & -7.8 \\
\hline Property Damage + & 1,888 & 1,775 & -6.0 \\
\hline Property Damage - & 590 & 509 & -13.7 \\
\hline Total & 4,239 & 3,907 & -7.8 \\
\hline
\end{tabular}


A final set of analyses focused on the police-reported possible contributing circumstance of a crash (Table 3.11). Crashes were selected if the investigating law enforcement officer indicated a driver factor considered "aggressive." The number of crashinvolved drivers with at least one aggressive contributing factor declined by 18.6 percent for the target corridors and by 8.1 percent for the comparison corridors.

Table 3.11

Crash-involved Drivers with at Least One Aggressive Factor as Possible Crash Contributing Circumstance Target and Comparison Roadway Corridors and Citywide City of Milwaukee April-September 1998, 1999

\begin{tabular}{|l|r|r|r|}
\hline & 1998 & 1999 & $\begin{array}{r}\text { Percent } \\
\text { Change } \\
\mathbf{1 9 9 8 / 9 9}\end{array}$ \\
\hline Target Corridors & & & \\
\hline Exceeding Speed Limit & 18 & 13 & -27.8 \\
\hline Speed Too Fast for Conditions & 33 & 20 & -39.4 \\
\hline Fail to Yield Right-of-Way & 229 & 185 & -19.2 \\
\hline Following Too Closely & $\mathbf{8 0}$ & 63 & -21.3 \\
\hline Making an Improper Turn & 32 & 32 & 0.0 \\
\hline Disregarding Traffic Comparison & 101 & 93 & -7.9 \\
\hline Improper Overtaking & 18 & 10 & -44.4 \\
\hline Total & $\mathbf{5 1 1}$ & 416 & $-\mathbf{1 8 . 6}$ \\
\hline Comparison Corridors & & & \\
\hline Exceeding Speed Limit & 12 & 12 & 0.0 \\
\hline Speed Too Fast for Conditions & 18 & 17 & -5.6 \\
\hline Fail to Yield Right-of-Way & 132 & 122 & -7.6 \\
\hline Following Too Closely & 71 & 54 & -23.9 \\
\hline Making an Improper Turn & 22 & 21 & -4.5 \\
\hline Disregarding Traffic Control & 73 & 75 & 2.7 \\
\hline Improper Overtaking & 6 & 6 & 0.0 \\
\hline & 334 & $\mathbf{3 0 7}$ & $-\mathbf{8 . 1}$ \\
\hline Total & & & \\
\hline
\end{tabular}




\section{CHAPTER 4: DISCUSSION}

The present results should be considered within the context of the state of knowledge about aggressive driving at the time the project was undertaken. As with any newly emergent area, there is much that remains to be discovered. Although there is a sense that we "know it when we see it," there is no set of agreed-upon measures to quantify aggressive driving. There are hypotheses about its causes and the circumstances that may trigger a specific incident, but these hypotheses have not been tested or made operational. We have better, but still incomplete, evidence about the types of drivers who are more likely to engage in aggressive acts. Better knowledge about the nature and causes of aggressive driving, and about at-risk drivers and driving situations, will aid especially in developing effective public awareness strategies that persuade drivers not to engage in this behavior.

It is clear, however, that there also is widespread belief among highway safety professionals and the public that aggressive driving is a growing problem that must be addressed. In response, states and communities have begun to develop programs and/or draft legislation. Ideal countermeasures should be based on an in-depth understanding of the scope and nature of the problem and the at-risk populations.

In initiating the Aggressive Driving Demonstration Projects, NHTSA's primary objective is to test the effectiveness of applying a well-tested general program model-a Selective Traffic Enforcement Program (STEP) - to aggressive driving. A STEP model employs publicized and intensified traffic enforcement at specific locations. The selection of the locations and the types of traffic offenses is based on an above-average number of crashes with contributing factors that are the result of particular types of offenses. The STEP model has proven effective in addressing different areas of highway safety, for example, DUI, speeding, occupant restraints.

There are other important objectives for these projects as well. One is to test alternative publicity and enforcement strategies, including the use of innovative technologies to identify and document aggressive driving behaviors. Another objective is to test the willingness, and the ability, of law enforcement officers to enforce a wide range of traffic offenses in addition to speeding. Finally, NHTSA hopes to expand the state of knowledge about how to define and measure different types of aggressive driving behaviors.

It is within this context that Milwaukee's Aggression Suppression Program was launched. The test site, the City and County of Milwaukee, has a history of strong traffic enforcement and successful community highway safety programs. A strong coalition to implement the program was in place. Historical crash and citation data enabled the program's planners to identify problem locations and ensured that the effects could be evaluated. The activities were well documented, and all evidence indicates the program was fully implemented as planned, with strong support from all partners. A thorough evaluation was conducted, with evidence gathered to establish the "causal chain" linking program activities and outputs with changes in drivers' attitudes and behaviors, and ultimately with reductions in crashes. 
How did the program fare in terms of the established objectives? The program was clearly successful in broadening enforcement efforts to target a wide range of aggressive driving offenses in addition to speeding violations. There were large percentage increases in the numbers of citations issued by the City and County agencies for non-speed violations. The program also succeeded in targeting enforcement to certain areas of the City and certain times.

Officers demonstrated enthusiastic support for the program. For the most part, the innovative equipment aided in enforcing aggressive driving offenses. The speed display boards, in-vehicle video cameras, and LTI laser speed detection devices were well received by officers. Enforcement agencies were able to identify other aspects of the enforcement program that worked especially well. These included the roll call videotape, which provided a good introduction to the program, and rotating the enforcement focus among different violations, which helped sustain officers' interest in the program. Other factors noted as particularly successful were the educational flyer on aggressive driving given to violators, the use of magnetic vehicle signs, and the intersection patrols. Officers were less enthusiastic about the LTI distance-between-cars technology; the process to obtain accurate measurements of distances was complex.

In terms of the publicity component, considerable earned coverage was generated, especially at the outset. Twelve media events were held. Many publicity materials were distributed. Paid advertising was not considered for this demonstration because law enforcement agencies wishing to replicate the successes in Milwaukee would likely not have funds for paid media. However, it is doubtful that the campaign was able to saturate the media market, which may be needed to have a demonstrable effect on the general driving public's attitudes and behaviors.

A much more intensive an/or much more focused publicity effort may be needed to produce greater changes in the public's attitudes and behaviors, especially in a community like Milwaukee with a long history of highway safety programs and strong enforcement. The use of enforcement/publicity sub-themes appears to have been successful in sustaining the interest of the media and participating enforcement agencies. Other apparently successful strategies were staging novel media events (for example, patrol ride-alongs) and highlighting innovative enforcement technologies and strategies. However, the multiple messages, each presented only briefly, may not have had the reinforcing effect of a sustained message necessary to change overall public attitudes. The more direct, straightforward sub-themes (for example, Rude Attitude Patrol) appeared to have more effect than the more indirect, subtle sub-themes (for example, Kindergarten Patrol or Basket Patrol).

With regard to changes in motorists' driving behaviors, videotapes of traffic at target and comparison intersections proved to be a feasible method for measuring the extent of red light-running. The analysis of before/during/after data indicated a decline in red light-running at the targeted intersections between the pre-program and mid-program periods. Although suggestive of program effect, this evidence must be viewed cautiously; enforcement was intensively targeted to these intersections, but heightened enforcement also occurred citywide.

The use of videotapes to document other types of aggressive driving on a major highway was less successful. (The highway segment videotaped was not targeted for special enforcement.) The identification and coding of aggressive behaviors on the highway proved 
to be problematic in several respects, due to the camera's limited field of view, heavy traffic congestion, and the inability to account for varying traffic volume, speed, and density. The process of coding these videotapes also highlighted the difficulty of using observational data to judge whether a given incident occurring in a very limited span of time and space is "aggressive." Many types of aggressive driving involve a series of behaviors.

The results with regard to motorists' self-reported behaviors and attitudes were mixed. Based on surveys of the general driving population, changes in motorists' perceptions of the strictness of enforcement did not occur, but the pre-program survey indicated that there was already a high level of perceived strictness of enforcement in Milwaukee. Most of the selfreport measures of attitudes and behaviors remained relatively flat across the three waves of the survey. However, drivers in the mid-program survey were significantly more likely than drivers in the pre-program survey to believe that they would be ticketed for running a red light or for running a stop sign. Drivers in the mid-program survey also were more likely to believe that running a red light or driving through a stop sign was always/nearly always a problem. The level of awareness of the specific campaign themes was low in all three waves of the survey. However, statistically significant increases in the level of awareness occurred for the themes of Rude Attitude Patrol, Courtesy Patrol, Space Patrol, and the State's concurrent "Let It Ride" campaign. Given the timing of the baseline survey, information was not available on the level of awareness of the overall campaign theme of Aggression Suppression.

Analyses of before/after crash data suggested that the program was associated with declines in crashes citywide. Overall levels of crashes declined significantly in the City, and the reductions were greatest on the roadway corridors targeted by special enforcement.

In sum, the Aggression Suppression Program demonstrated the effects of targeted enforcement. More citations were issued for aggressive driving types of violations (that is, not just speed tickets were issued); motorist behavior changed at targeted intersections; and crash reduction was demonstrated citywide, with greater reductions on corridors with targeted enforcement. Future programs of this type would be enhanced if they could generate more visible and more focused media attention. 


\section{REFERENCES}

Boyle, J., Dienstfrey, S., Sothoron, A. (1998) Nationwide Survey Regarding Speeding and Other Unsafe Driving Actions. DTNH22-95-C-05096. National Highway Traffic Safety Administration, Washington DC.

Goehring, J.B. (2000) Aggressive Driving: Background and Overview Report. Denver, CO: National Conference of State Legislatures.

McCartt, A.T., Hammer, M.C., Ribner, S., Keeler, M.A., Swartz, S. (1998) Spring 1998 Telephone Survey of New York State Licensed Drivers, Volume 1: Highway Safety Issues. Institute for Traffic Safety Management and Research.

National Highway Traffic Safety Administration. (1998) Strategies for Aggressive Driver Enforcement. DOT HS 808 744. Washington, DC.

National Highway Traffic Safety Administration. (2000) Aggressive Driving Enforcement: Strategies for Implementing Best Practices. DOT HS 809 031. Washington, DC.

National Highway Traffic Safety Administration. (2001) Aggressive Driving Prosecutors' Planner. Washington, DC.

National Highway Traffic Safety Administration and Federal Highway Administration. (1999) Aggressive Driving and the Law: A Symposium. DOT HS 808 920. Washington, DC.

Preusser Research Group, Inc. (1998) Capital Beltway Update: Beltway User Focus Groups. DOT HS 808 705. National Highway Traffic Safety Administration, Washington DC.

RSM, Inc. (1997) 1997 AAA Potomac Transportation Poll. Rockville, Maryland.

Savage, M.A. (2000) State Traffic Safety Legislative Summary 2000. NCSL Transportation Series, December 2000, No. 15. Denver, CO: National Conference for State Legislatures. 
DOT HS 809395

May 2001

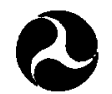

U.S. Department of Transportation National Hlohwoy

Treftic Satoty

Administration

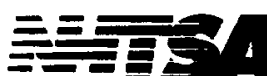

Poria soulu Por!?

conitived 